\title{
Ocupaciones alfareras tempranas. Tecnología y subsistencia en el piedemonte del norte de Mendoza (Centro Oeste Argentino)
}

\section{Early pottery occupations. Technology and subsistence in the piedmont of northern Mendoza (West-central Argentina)}

\author{
Horacio Chiavazza ${ }^{1,2}$ (D) https://orcid.org/0000-0003-1632-8388 \\ Cristina Prieto-Olavarría ${ }^{1,2,3}$ (iD) https://orcid.org/0000-0002-8735-6776 \\ Lorena Puebla ${ }^{1,2}$ (D) https://orcid.org/0000-0002-2979-6044 \\ Marcos Quiroga 4 (D) https://orcid.org/0000-0003-3813-4760 \\ Leonardo Castillo $^{1,2}$ (D) https://orcid.org/0000-0002-4105-1512 \\ Jorge Anzorena2 (D) https://orcid.org/0000-0002-0644-7888 \\ José Manuel López ${ }^{1,5}$ (D) https://orcid.org/0000-0003-0383-1558 \\ Luis Mafferra',3 (D) https://orcid.org/0000-0002-3966-6833 \\ Valeria Zorrilla ${ }^{1,2,6}$ (D) https://orcid.org/0000-0001-6306-6371 \\ Daniela Alit Mansegosaa ${ }^{2,4}$ (D) https://orcid.org/0000-0002-2106-8536 \\ Pablo Sebastián Giannotti ${ }^{2,4}$ (iD) https://orcid.org/0000-0001-5737-6058
}

${ }^{1}$ Universidad Nacional de Cuyo, Facultad de Filosofía y Letras, Instituto de Arqueología y Etnología, Laboratorio de Arqueología Histórica y Etnohistoria, Mendoza, ARGENTINA.

Email: hchiavazza@gmail.com; cprieto@mendoza-conicet.gob.ar; lorenaivanapuebla@gmail.com; leocastillounc@gmail.com; mlopez@mendoza-conicet.gob.ar; luismafferra@gmail.com; zorrillavaleria@gmail.com;

${ }^{2}$ Centro de Investigaciones Ruinas de San Francisco, Área Fundacional Municipalidad de Mendoza, Municipalidad de Mendoza, Mendoza, ARGENTINA. Email: jorgeanzorenaunc@gmail.com; alitmansegosa@gmail.com; pablosebastiangiannotti@gmail.com;

${ }^{3}$ Instituto Argentino de Nivología, Glaciología y Ciencias Ambientales, Centro Científico Tecnológico, Consejo Nacional de Investigaciones Científicas y Técnicas, Mendoza, ARGENTINA.

${ }^{4}$ Universidad Nacional de Cuyo, Facultad de Filosofía y Letras, Instituto de Arqueología y Etnología, Consejo Nacional de Investigaciones Científicas y Técnicas, ARGENTINA.

Email: marcos.graco@gmail.com.

${ }^{5}$ Instituto Argentino de Investigaciones de las Zonas Áridas, Consejo Nacional de Investigaciones Científicas y Técnicas, Centro Científico Tecnológico, Mendoza, ARGENTINA.

${ }^{6}$ Museo de Ciencias Naturales y Antropológicas Juan Cornelio Moyano, Mendoza, ARGENTINA. 


\title{
Resumen
}

Las excavaciones en el sitio Memorial de la Bandera ubicado en la ciudad de Mendoza, faja central del Centro Oeste Argentino, permitieron recuperar evidencias del asentamiento humano en el piedemonte normendocino. Este sector contaba con escasas referencias arqueológicas debido al amplio desarrollo urbano. En este trabajo se analizan rasgos y materiales, con el objetivo de conocer las características de las ocupaciones y subsistencia en el piedemonte, su cronología y el desarrollo de la tecnología lítica y cerámica. Los fechados indican que el sitio fue ocupado entre ca. 2100 y 1200 años AP y es uno de los más tempranos registrados en el área. Se plantea la estabilidad del asentamiento y el posible cultivo, a partir de la evidencia de casas semisubterráneas, los rasgos de combustión y los restos vegetales. La temprana ocupación de este ambiente se relacionaría con la incorporación de la tecnología cerámica en la región. Su ubicación al costado de un cauce aluvional y la particularidad de los restos arqueofaunísticos y antracológicos indican la posible existencia de humedales en el pasado. La tecnología lítica y los restos arqueofaunísticos, permiten discutir estas ocupaciones en el marco del proceso de intensificación económica postulado para la región y el Cono Sur.

Palabras clave: Holoceno Tardío, intensificación, casas semisubterráneas, cerámica temprana, plantas cultivadas.

\begin{abstract}
The extensive excavations at the Memorial de la Bandera site in the city of Mendoza, central zone of west-central Argentina, has allowed the recovery of evidence of human settlement in the foothills of northern Mendoza province. This area had shown few archaeological references due to extensive urban development. In this work, features and materials are analyzed, in order to understand the characteristics of the occupations and their subsistence in the foothills, their chronology and their development of lithic and ceramic technology. Radiocarbon dating indicates that the site was occupied between ca. 2100 and 1200 years BP, making it one of the earliest recorded in the piedmont of northern Mendoza province. The stability of settlement and possible cultivation is suggested based on the evidence of semi-subterranean houses, combustion traces and plant remains. The early occupation in this environment is related to the incorporation of ceramic technology in the region. Both its location next to an alluvial channel and the characteristic of archaeofaunal and anthracological remains indicate the possible existence of wetlands in the past. The lithic technology and archaeofaunal remains allow discussion about these occupations within the framework of the economic intensification process postulated for the region and the Southern Cone.
\end{abstract}

Keywords: Late Holocen, intensification, semi-subterranean houses, early pottery, cultivated plants.

Recibido: 14 septiembre 2020. Aceptado: 1 marzo 2021 


\section{Introducción}

El piedemonte del norte de Mendoza (Centro Oeste Argentino, COA en adelante), posee evidencia de ocupaciones humanas pasadas, pero su investigación se ha dificultado, ya que gran parte se encuentra en el sustrato del conurbano mendocino. Las investigaciones arqueológicas se desarrollaron desde la primera mitad del siglo XX, pero solo algunos sectores cuentan con investigaciones sistemáticas, como las realizadas en el Área Fundacional. Las escasas referencias existentes para otros sectores indican que las primeras ocupaciones humanas del piedemonte se produjeron hace aproximadamente 2000 años (Rusconi, 1962; Bárcena, 1998; Chiavazza, 2005). Estas ocupaciones coinciden temporalmente con los importantes cambios registrados en los modos de vida cazador-recolector de las poblaciones del Cono Sur durante el Holoceno Tardío. Las transformaciones se caracterizaron por la incorporación de la tecnología cerámica, la explotación de los recursos locales (incluida la incorporación de vegetales cultivados), la diversificación de la dieta, la reducción de los patrones de movilidad, el aumento demográfico y la ocupación de áreas marginales (Politis, Martínez y Bonomo, 2001; Morgan et al., 2017). En el COA, estos cambios se han interpretado como parte de un proceso de intensificación regional (Cortegoso, 2006; Chiavazza, 2007, 2013; Neme, 2007; Corbat, Zangrando, Gil y Chiavazza, 2017; Gil, Giardina et al., 2014; López, 2018).

En este trabajo se analiza la evidencia de ocupaciones humanas tempranas recuperadas en el sitio Memorial de la Bandera (MB en adelante), a partir de excavaciones realizadas en área abierta. Este se ubica en el piedemonte del norte de Mendoza, en el sector históricamente conocido como valle de Mendoza o Huentota, concretamente en el centro cívico de la ciudad de Mendoza. Los objetivos son: aportar al conocimiento del proceso de ocupación; el uso y características del ambiente; la subsistencia y la tecnología en el primer milenio de la era en este sector del piedemonte de Mendoza, y contribuir a la discusión sobre posibles procesos de intensificación en el norte de Mendoza. Para lograr estos propósitos, se analizó el material zooarqueológico, arqueobotánico, lítico y cerámico, y se realizaron fechados radiocarbónicos.

\section{Ocupaciones humanas y procesos de intensificación en el COA}

Las ocupaciones humanas más tempranas del norte de Mendoza se registran en la puna precordillerana a inicios del Holoceno, hace unos 11.000 años AP (García, 2003). Durante este lapso y hasta aproximadamente los 2000 años AP, se desarrolló una economía basada en la caza y la recolección, la que se mantuvo hasta el Holoceno Tardío, si bien en la llanura se incorporó la pesca hace unos 3000 ańos (Chiavazza, 2010, 2013). Hace aproximadamente 2000 años, se registran cambios en los contextos arqueológicos del COA, entre los que destaca la ocupación de nuevos ambientes, la aparición de estructuras habitacionales, novedades en la tecnología lítica y aprovisionamiento de materias primas, la incorporación de alimentos cultivados (principalmente maíz, calabaza, poroto y quínoa) y de la cerámica (Cortegoso, 2006; Neme, 2007; Marsh, 2017; Prieto-Olavarría et al., 2017). Se propuso que esto obedecía al paso de una economía centrada en la caza y la recolección a otra agrícola de carácter sedentario (Lagiglia, 2001). Nuevas perspectivas en la investigación plantearon que estos cambios obedecían a un proceso de regionalización y cambios económicos hacia economías mixtas, cuyo alcance habría sido macrorregional, ya que también se observan en Sierras Centrales, San Juan y Chile Central (Gambier, 1993; Durán, 2000; Cornejo y Sanhueza, 2003; Planella y Tagle, 2004; Neme, 2007; Pastor, Medina y Berberián, 2013; Ots, Aguilar, Cahiza y García Llorca, 2016). 
En el área vecina del suroeste de San Juan se planteó el temprano consumo de productos agrícolas entre los ca. 3800 a 2200 ańos AP, como resultado de una agricultura incipiente (Gambier, 1993). Posteriormente, se propuso que en este período las evidencias serían resultado del intercambio más que de la producción local, en un proceso de transición al sedentarismo (García, 2010). Hacia los ca. 2200 y 1300 años AP, se produjo el desarrollo aldeano y pastoril, con llamas domesticadas hacia los 1500 ańos AP. Justamente, en este lapso se detectan evidencias de estructuras habitacionales, casas semisubterráneas, de almacenamiento y sistemas de cultivo que se asociaron con aumentos demográficos (Gambier, 1993). Gambier (1977) reportó estructuras habitacionales semisubterráneas en Calingasta, datándolas entre ca. 1700 y 1200 años AP. Es en este período cuando la alfarería y la presencia de elementos de origen exótico señalan un incremento en las redes de intercambio entre poblaciones de San Juan, el NOA (Aguada) y Norte Chico chileno (Molle) (Gambier, 1993). En relación a las poblaciones ubicadas al este, en Sierra de Comechingones (Córdoba), se plantea que entre los ca. 2500 y 1000 años AP se desarrolló agricultura de baja escala, con el mantenimiento de la caza y recolección e innovaciones tecnológicas entre las que se destaca la cerámica temprana (Pastor, Medina y Berberián, 2013).

En el sur de Mendoza, se propone que entre los ca. 2000 y 1500 años AP se produjo la colonización de nuevos hábitats en las tierras altas y bajas, lo que habría sido parte del proceso de ampliación de la base de subsistencia a partir de la intensificación en el uso de los recursos animales y vegetales, acompañados por numerosas estrategias relacionadas con cambios en el patrón de asentamiento, la organización tecnológica y la reducción de la movilidad (Neme, 2007). La causa habría sido el aumento en la presión demográfica regional y el consecuente impacto de las poblaciones humanas sobre la estructura regional de recursos (Neme, 2007; Neme y Gil, 2008, 2009; Morgan et al., 2017). Este desbalance habría generado la necesidad de que los grupos humanos cambiaran las estrategias de explotación y la tecnología, lo que se tradujo en la sobreexplotación del paisaje y la disminución de los recursos altamente ranqueados (como el guanaco), por lo que la subsistencia se orientó a la explotación de recursos con bajos rendimientos calóricos y mayores costos de procesamiento, estimulando la adopción de plantas cultivadas como el maíz (Gil, Tykot, Neme y Shelnut, 2006; Neme, 2007). En el caso del norte de Mendoza, concretamente en la precordillera, este proceso se manifestó en cambios en la explotación de recursos, la organización de la tecnología lítica, la reducción de la movilidad y el asentamiento en casas semisubterráneas (Cortegoso, 2006; Gasco, Marsh, Frigolé, Castro, Privitera, Moyano y Yebra, 2011; Chiavazza, 2014). Desde esta perspectiva, el proceso de intensificación se asocia tanto a la disminución de la eficiencia de aprovisionamiento (intensificación sensu stricto) como a cualquier incremento de la productividad (intensificación sensu lato, por ejemplo, diversificación, innovación, especialización), incluyendo aquellas actividades que aumentan la eficiencia de las sociedades humanas (Morgan, 2015). Ambas acepciones pueden resultar complementarias y no excluyentes entre sí (López, 2018).

En este contexto de las investigaciones de la región y áreas vecinas es que el análisis del registro arqueológico del sitio $\mathrm{MB}$, ubicado en un área escasamente investigada desde la arqueología, puede aportar valiosa información para entender procesos de ocupación del territorio, explotación de los recursos y los cambios tecnológicos en la subárea COA.

\section{Área de estudio y ubicación del sitio Memorial de la Bandera}

El COA se ubica entre los $32^{\circ}$ y $37^{\circ}$ latitud Sur, sobre parte de la Diagonal Árida Sudamericana (Figura 1A). El norte de Mendoza ocupa la franja central (Figura 1B) y posee un clima árido-semiárido, con un promedio de precipitaciones anuales de alrededor de $200 \mathrm{~mm}$ (Abraham, 2000). 
La región posee déficit hídrico y en el sector del desierto de Monte el aumento de la temperatura e irradiación solar determinan que el balance hídrico sea permanentemente negativo (Bagnouls y Gaussen, 1957). Para los ambientes áridos y semiáridos del norte mendocino, y desde una perspectiva biogeográfica, se propone que el agua es un recurso crítico que influye en la estructura de recursos (animales y plantas) e incide en la toma de decisiones respecto al asentamiento, lo cual permite explicar el patrón de asentamiento humano en la región (Chiavazza, 2014).

El piedemonte y la llanura están expuestos a la acción de los anticiclones del Atlántico y se integran en la Provincia Fitogreográfica del Monte (Roig, 1972), caracterizada por comunidades arbustivas densas (principalmente Larrea sp., Schinus sp.) y un estrato arbóreo dominado por Prosopis flexuosa (Roig, Martínez Carretero y Méndez, 2000), entre otras especies (p.e., Geoffrea decorticans). Las montańas ubicadas al oeste tienen una elevación media de aproximadamente $3500 \mathrm{msnm}$ con varios picos entre los 5000 y $6000 \mathrm{msnm}$ y colinda al este con la depresión pedemontana y la planicie, que se extiende con inclinación hacia el este hasta el río Desaguadero, con alturas entre 1500 y $300 \mathrm{msnm}$ (Roig, 1976). Desde el punto de vista de la fauna de la provincia del Monte, destaca la presencia de guanaco y ñandú (Lama guanicoe y Rhea

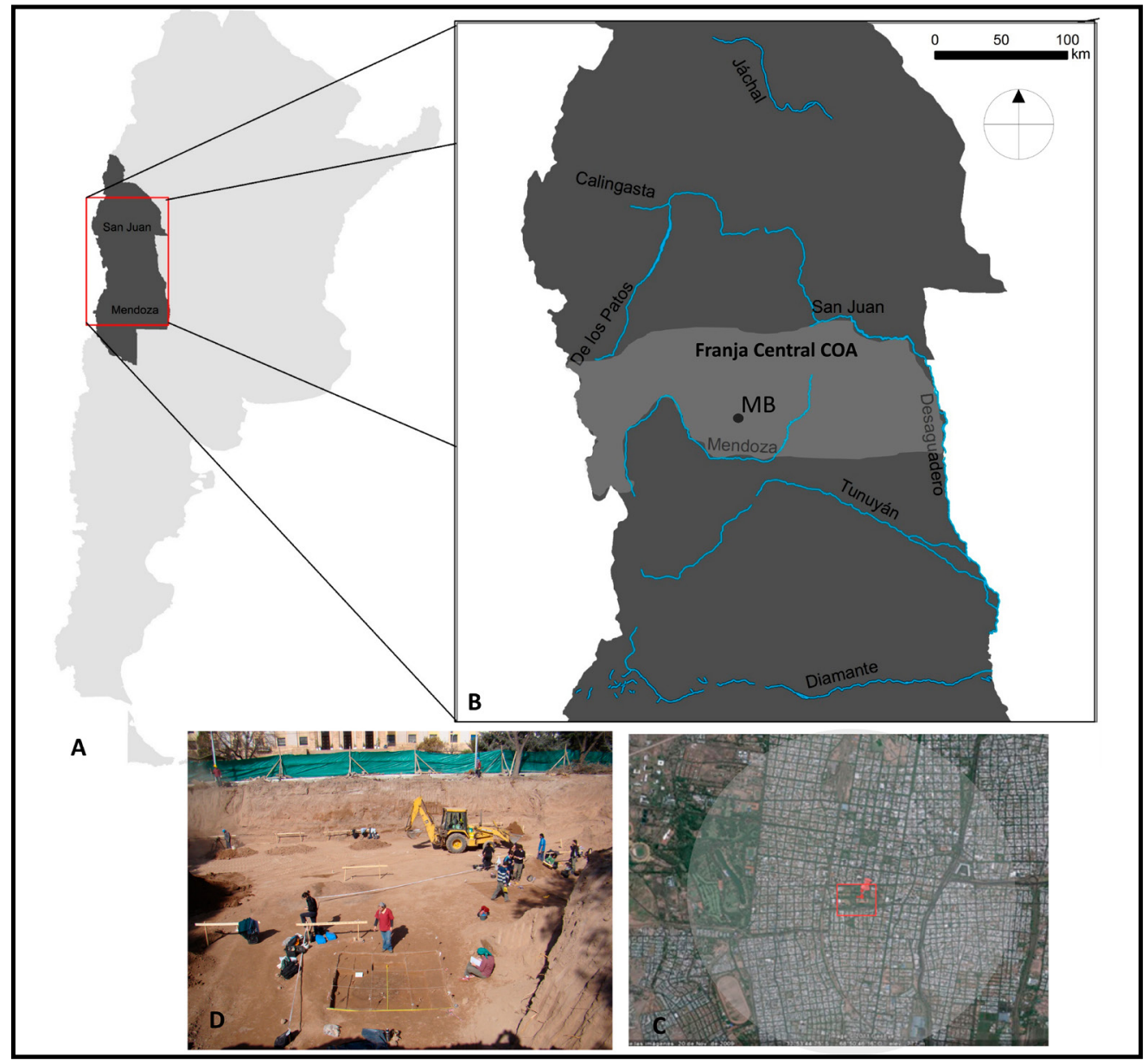

Figura 1. A) El Centro Oeste Argentino en contexto regional; B) Centro Oeste, franja central y localización de MB (Memorial de la Bandera); C) Ubicación de las excavaciones en pleno Centro Cívico de Mendoza; D) Vista general de la excavación en el contexto de obras. 
americana), una relativa diversidad de aves y mamíferos de porte mediano (Eudromia elegans, Nothura maculosa, Dolichotis patagonum), además de fauna pequeña y muy pequeña entre la que destacan variedades específicas de dasipódidos y rodentia. En las lagunas y cursos de agua se encuentran peces, como la trucha (Percichtys trucha), bagre y pejerrey (Odontesthes cuyanus).

El sitio MB se ubica en la depresión del piedemonte (por debajo de $1000 \mathrm{msnm}$ ) (Figura 1B), al este de la precordillera del norte de Mendoza y en la margen izquierda de un cauce aluvional (Zanjón Frías). Este amplio glacis de pendiente suave está modelado por la escorrentía resultante de lluvias de verano que discurren con intensidad por su posición al pie de la precordillera, produciendo remociones y arrastres masivos de arenas, gravas y arcillas con fuertes procesos de agradación sedimentaria (Roig, 1976). En este sector se ubica la ciudad de Mendoza, fundada en 1561, momento a partir del cual se desarrolla la expansión urbana y el principal oasis productivo del oeste argentino. Estudios documentales indican que al inicio de la Colonia este sector presentaba un ambiente propio del jarillal (Larrea sp.), conocido localmente como "carrascal" en referencia a la vegetación arbustiva (posiblemente molle, Schinus molle) (Prieto y Wuilloud, 1986). Actualmente, por encima de los $1200 \mathrm{msnm}$ predomina el piso de Larrea divaricata, que se extiende hasta los ca. 1600 msnm y asciende por las laderas de exposición sur de las quebradas, mientras que a menor altitud se comporta como vegetación riparia; por debajo de los 1200 y hasta los $750 \mathrm{msnm}$ predomina el piso de Larrea cuneifolia (Vaccarino Pasquali, Manduca, Bizzoto y Vich, 2012). Actualmente, esta vegetación es casi inexistente en el sector urbano.

En una escala menor, el sitio se encuentra en la margen norte del Zanjón Frías, que es una de las cinco cuencas aluvionales de carácter torrencial que descienden desde la precordillera y proveen de agua al valle de Mendoza. Asociadas a estos zanjones se han registrado ocupaciones humanas tempranas en torno a los ca. 2000 años AP. (Bárcena, 1998; Chiavazza, 2005, 2010; Prieto y Chiavazza, 2006; Chiavazza, Frías, Puebla y Acosta, 2008; Chiavazza, Prieto-Olavarría, Puebla, Quiroga, Anzorena y Bontorno, 2019).

\section{El sitio Memorial de la Bandera y la arqueología urbana}

Las obras públicas realizadas durante la primera mitad del siglo XX en Mendoza dejaron al descubierto contextos arqueológicos bajo la ciudad. Durante la construcción del centro cívico, que incluyó el edificio de Casa de Gobierno y el Palacio de Justicia, se reportó la aparición de hornillos, restos líticos, cerámicos y huesos humanos entre los 2 y $8 \mathrm{~m}$ de profundidad (Rusconi, 1956, 1962). El año 2011, en la explanada ubicada frente a la entrada de la Casa de Gobierno, se realizó una gran excavación para construir el Memorial de la Bandera, labor que requirió hacer tareas de seguimiento y rescate arqueológico ${ }^{1}$ (Figura 1C). Las características de la obra y las gestiones realizadas permitieron hacer, por primera vez en el piedemonte, una excavación en área abierta y recuperar gran cantidad de rasgos y materiales arqueológicos ubicados a más de $4 \mathrm{~m}$ de profundidad. La evaluación de la estratigrafía hasta $8 \mathrm{~m}$ de profundidad permitió precisar que los aportes sedimentarios resultaron de la agradación por acción fluvial procedente del piedemonte con contribuciones de diferente intensidad, ya que se observaron bolsadas de gravas, ripios y cantos rodados intercalados con limos arcillo-arenosos.

Durante la obra, se supervisaron $2400 \mathrm{~m}^{2}$ y se identificaron 15 rasgos arqueológicos entre los 430 y $450 \mathrm{~cm}$ de profundidad, en un área de $130 \mathrm{~m}^{2}$. Los rasgos se encontraban en sincronía

1 Realizadas por el equipo del CIRSF, Centro de Investigaciones Ruinas de San Francisco, Municipalidad de Mendoza, Argentina. 
estratigráfica relativa y con una potencia arqueológica que variaba entre 1 y $40 \mathrm{~cm}$ aproximadamente (Chiavazza, 2015) (Figura 1D y Tabla 1). El análisis de las estructuras y los resultados preliminares de los materiales permitieron plantear que correspondían a hornillos, casas semisubterráneas, rasgos de combustión y posibles estructuras asociadas al manejo del agua (canales y cisterna) (Tabla 1) (Chiavazza, 2013, 2015). A esto se sumó la recuperación de un hornillo en niveles superiores (180 cm de profundidad), con restos materiales correspondientes al período de dominación inca y de la conquista (Chiavazza, 2015) y un rasgo carbonoso a aproximadamente $5 \mathrm{~m}$ de profundidad. Este hiatus es una constante en el piedemonte de acuerdo a lo que se puede observar en diversas excavaciones realizadas en la ciudad (Chiavazza et al., 2019).

Tabla 1. Rasgos del sitio Memorial de la Bandera, sus características generales y actividades inferidas. La información de los rasgos 1 a 7 y 9 a 10 se tomaron de Chiavazza (2015).

\begin{tabular}{|c|c|c|}
\hline & Características generales & Actividades inferidas \\
\hline Rasgo 1 & $\begin{array}{l}\text { Planta circular con carbón, cenizas y diversidad de materiales: } \\
\text { conanas, manos de moler, lascas con filos naturales y retocados, } \\
\text { cerámica, huesos de fauna y semillas carbonizadas. }\end{array}$ & $\begin{array}{l}\text { Habitacional. } \\
\text { Casa semisubterránea }\end{array}$ \\
\hline Rasgo 2 & Carbón disperso, cerámica y líticos. & Área de circulación \\
\hline Rasgo 3 & $\begin{array}{l}\text { Planta circular con carbón, cenizas y diversidad de materiales: } \\
\text { conanas, manos de moler, lascas con filos naturales y retocados, } \\
\text { cerámica, huesos de fauna y semillas carbonizadas. }\end{array}$ & $\begin{array}{l}\text { Habitacional. } \\
\text { Casa semisubterránea }\end{array}$ \\
\hline Rasgo 4 & $\begin{array}{c}\text { Concentración de nódulos de arcilla y lentes de arena fluvial con } \\
\text { espículas de carbón dispersas. }\end{array}$ & $\begin{array}{l}\text { Posible área de producción } \\
\text { alfarera }\end{array}$ \\
\hline Rasgo 5 & Pozo con rocas, huesos termoalterados y cerámica. & Área de cocción de alimentos \\
\hline Rasgo 6 & Concentración de nódulos de arcilla y arena. & $\begin{array}{l}\text { Posible área de producción } \\
\text { alfarera }\end{array}$ \\
\hline Rasgo 7 & Rasgo de ocupación alargado muy carbonoso con abundante lítico. & $\begin{array}{c}\text { Área de procesamiento y talla } \\
\text { lítica }\end{array}$ \\
\hline Rasgo 8 & Hornillo. & $\begin{array}{l}\text { Combustión intensa en horno } \\
\text { con diseño específico }\end{array}$ \\
\hline Rasgo 9 & $\begin{array}{l}\text { Rasgo cerrado de forma globular con matriz arcillosa fina que } \\
\text { contenía caracolillos y manchas carbonosas. } \\
\text { Evidencias de encharcamiento. }\end{array}$ & $\begin{array}{l}\text { Posible depósito de agua o } \\
\text { cisterna }\end{array}$ \\
\hline Rasgo 10 & $\begin{array}{l}\text { Rasgo alargado, poco profundo, de base cóncava con matriz arenosa } \\
\text { con espículas de carbón. Orientado hacia el Rasgo } 9 .\end{array}$ & Posible canal \\
\hline Rasgo 11 & $\begin{array}{l}\text { Rasgo alargado, poco profundo, de base cóncava con matriz arenosa } \\
\text { con espículas de carbón. Orientado hacia el Rasgo } 9 .\end{array}$ & Posible canal \\
\hline Rasgo 12 & $\begin{array}{c}\text { Asociado al rasgo 11, como rasgo preexistente con carbón y nódulos } \\
\text { de arcilla. }\end{array}$ & Indeterminado \\
\hline Rasgo 13 & Asociado al rasgo 10 , como rasgo preexistente con carbón. & Indeterminado \\
\hline Rasgo 14 & $\begin{array}{c}\text { Planta circular con materiales y gran cantidad de carbón. } \\
\text { Materiales, cerámicos y líticos. }\end{array}$ & $\begin{array}{l}\text { Habitacional. } \\
\text { Casa semisubterránea }\end{array}$ \\
\hline Rasgo 15 & $\begin{array}{l}\text { Carbón asociado a sedimentos termoalterados. } \\
\text { Por debajo de la cota de }-5.50 \mathrm{~m} \text {. }\end{array}$ & $\begin{array}{l}\text { Sector de combustión preexis- } \\
\text { tente a nivel estratigráfico }\end{array}$ \\
\hline
\end{tabular}




\section{Métodos}

Se realizaron dataciones radiocarbónicas al carbón recuperado de los rasgos. Las cinco dataciones obtenidas se sumaron a otras 47 realizadas en sitios del norte de Mendoza, buscando establecer componentes con sincronía relativa. Para ello se utilizó el programa CALIB REV. 7.0.4. (Stuiver, Reimer y Reimer, 2005), que convierte la edad de radiocarbono en años calendario y los calibra mediante el cálculo de una distribución de probabilidad de la edad de la muestra. Esto permite definir si se ubican o no estadísticamente a un mismo nivel cronológico por medio de porcentajes de coincidencia o diferencia. Primero, se chequeó la totalidad de la muestra (que demostró un $95 \%$ de falta de correspondencias sincrónicas) y luego se agruparon, desde las más antiguas a las más recientes, conjuntos de muestras que tuvieran niveles de coincidencia significativa en el orden del 95\%, para así obtener componentes temporales comparables en toda la franja central del COA.

El análisis antracológico se realizó siguiendo el protocolo detallado por Mafferra (2015). Para identificar los taxa se observaron las características anatómicas y se cotejaron con la colección de referencia y bibliografía especializada (Castro, 1994; InsideWood, 2004; Mafferra, Roig y Piraino, 2013). Para confirmar las asociaciones taxonómicas, algunos ejemplares de cada taxón fueron analizados con microscopio electrónico de barrido (JEOL JSM-6610LV 30kv). Las muestras fueron cuantificadas mediante el conteo de los fragmentos y la medición de su volumen aproximado (Mafferra, 2015). Para interpretar los datos con base en el resultado de la medición de volumen, se calculó la frecuencia (Piqué i Huerta, 1999; Scheel-Ybert, 2004) y la diversidad (Shannon H', Past 3.0) (Hammer, Harper y Ryan, 2001). Los restos zooarqueológicos se analizaron siguiendo criterios generales establecidos para definir taxa y establecer índices de diversidad y homogeneidad (Mengoñi Goñalons, 2010).

Los materiales líticos se estudiaron tecnotipológicamente para analizarlos dentro de un sistema de producción (Collins, 1975; Aschero, 1983; Ericson, 1984). Se analizó la procedencia de las rocas y minerales a partir de la comparación con los catálogos disponibles de materias primas locales (Chiavazza, 1995; Chiavazza y Cortegoso, 2004; Cortegoso, Lucero, Castro y Winocur, 2017). El análisis cerámico se enfocó desde una perspectiva tecnológica, funcional y de las huellas de uso, para lo cual se analizó el tratamiento de superficie, espesor, forma, decoración, atmósfera de cocción y huellas de uso (Shepard, 1956; Rice, 1987; Rye, 1981; Skibo, 1992, 2015).

\section{Resultados}

\section{Ocupación y cronología}

La ocupación del sitio se habría realizado por medio del establecimiento de casas semisubterráneas, las que son pozos de planta circular con diámetros que oscilaban entre los 150 y 250 $\mathrm{cm}$. Se presentan como superficies con sedimento carbonoso, con profundidades entre los 30 y $40 \mathrm{~cm}$. Poseen concentraciones de artefactos, sedimentos termoalterados y en algunos casos improntas de postes carbonizados. No se han recuperado restos de quincha, como sí se han registrado en el noreste de Mendoza (Chiavazza, 2007).

Los seis fechados realizados en el sitio indican cinco componentes de ocupación (Tabla 2). Cuatro de ellos, CIII, CIV, CV y CVI, corresponden a dos casas semisubterráneas y rasgos de combustión ubicados en los niveles más profundos y tempranos, a unos $4 \mathrm{~m}$ (Tabla 2). 
El componente CX corresponde al hornillo más tardío, ubicado aproximadamente a $2 \mathrm{~m}$ de la superficie y datado en cal 370 AP. Excluyendo esta última, los fechados se inscriben en un lapso de 990 años de duración, que implica cuatro componentes sucesivos (CIII, CIV, CV y CVI) pero separados por hiatus de duración variable: 30 ańos entre CIII y CIV; 300 años entre CIV y CV; 60 años entre CV y CVI. La congruencia estratigráfica relativa de los rasgos y unidades identificadas hace depender cualquier interpretación a la disponibilidad de más dataciones, para definirlos como parte de los mismos o diferentes lapsos de uso, ya que los rasgos poseen amplia distribución espacial y espesores que rondan entre 1 y $40 \mathrm{~cm}$ de potencia, generando palimpsestos y consecuentemente una baja resolución temporal.

Los componentes (C) del contexto regional se calcularon agrupando los fechados del sitio con dataciones sincrónicas y por medio de CALIB REV. 7.0.4. (Stuiver et al., 2005). Se consideraron 52 dataciones correspondientes al norte de Mendoza, de precordillera y planicie, con fechas entre ca. 4000 y 400 años AP.

Tabla 2. Seis dataciones radiocarbónicas de diversos rasgos del sitio MB.

\begin{tabular}{|c|c|c|c|c|c|c|c|c|}
\hline 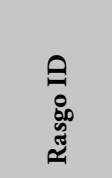 &  & 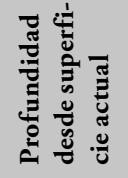 & 吾 & 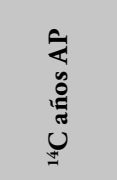 & ত̃ & U. & 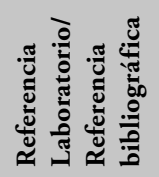 & 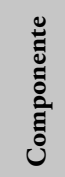 \\
\hline $\begin{array}{l}\text { Hornillo } \\
\text { tardío }\end{array}$ & $\begin{array}{c}\text { Boca, en la } \\
\text { superficie de } \\
\text { uso }\end{array}$ & $\begin{array}{l}180-200 \\
\mathrm{~cm}\end{array}$ & Carbón & $370 \pm 50$ & $\begin{array}{c}1497 \mathrm{a} \\
1528\end{array}$ & $-24 \pm 2 \%$ o & $\begin{array}{c}\text { Latyr } \\
\text { LP2645 } \\
\text { Chiavazza } \\
\text { 2015: } 52\end{array}$ & $\mathrm{CX}$ \\
\hline $\begin{array}{l}\text { Rasgo } \\
14 \\
\text { Sondeo } \\
2\end{array}$ & $\begin{array}{c}\text { Rasgo de } \\
\text { combustión } \\
\text { en casa semi- } \\
\text { subterránea }\end{array}$ & $\begin{array}{c}400-420 \\
\mathrm{~cm}\end{array}$ & Carbón & $1230 \pm 60$ & $\begin{array}{c}776 \mathrm{a} \\
899\end{array}$ & $-24 \pm 2 \%$ & $\begin{array}{c}\text { Latyr } \\
\text { LP2644 } \\
\text { Chiavazza } \\
\text { 2015: } 52\end{array}$ & CVI \\
\hline Rasgo 1 & $\begin{array}{l}\text { Casa semi- } \\
\text { subterránea }\end{array}$ & $\begin{array}{c}\text { Techo de } \\
\text { ocupación } \\
400-410 \\
\mathrm{~cm}\end{array}$ & Carbón & $1350 \pm 60$ & $\begin{array}{l}656 \mathrm{a} \\
769\end{array}$ & $-24 \pm 2 \%$ & LP3601 & CVI \\
\hline Rasgo 8 & $\begin{array}{l}\text { Hornillo en- } \\
\text { tre su base y } \\
\text { sector medio }\end{array}$ & $\begin{array}{l}450 \\
\mathrm{~cm}\end{array}$ & Carbón & $1499 \pm 31$ & $\begin{array}{l}420 a \\
482\end{array}$ & - & $\begin{array}{c}\text { D- } \\
\text { AMS030572 } \\
\text { AMS }\end{array}$ & $\mathrm{CV}$ \\
\hline Rasgo 3 & $\begin{array}{l}\text { Casa semi- } \\
\text { subterránea }\end{array}$ & $\begin{array}{c}\text { Techo de } \\
\text { ocupación } \\
400-410 \\
\mathrm{~cm}\end{array}$ & Carbón & $1910 \pm 80$ & $\begin{array}{l}55 \mathrm{a} \\
239\end{array}$ & $-24 \pm 2 \%$ & LP3180 & CIV \\
\hline Rasgo 3 & $\begin{array}{l}\text { Casa semi- } \\
\text { subterránea }\end{array}$ & $\begin{array}{c}\text { Base de } \\
\text { ocupación } \\
440-450 \\
\mathrm{~cm}\end{array}$ & Carbón & $2100 \pm 80$ & $\begin{array}{c}161 \mathrm{a} \\
24\end{array}$ & $-24 \pm 2 \%$ & LP3195 & CIII \\
\hline
\end{tabular}




\section{Análisis arqueobotánico}

Durante la excavación se intervinieron conjuntos y manchas carbonosas con gran cantidad de carbón y también se obtuvieron semillas individuales. Gran parte del material fue procesado y se recuperaron restos botánicos por medio de flotación y lavado de sedimentos (Figura 2A). Se identificaron 30 restos carpológicos, los que se analizaron macroscópicamente y fueron adscriptos preliminarmente a distintos géneros (Chiavazza y Mafferra, 2007; Mafferra, 2009) (Figura 2B).



Figura 2. A) Distribución de porcentajes de semillas por Rasgo (R) en el sitio $M B$. $S / R=$ sin rasgo. B) Restos carbonizados de Zea maíz del Rasgo 8, sitio MB.

La mayor parte de los restos carpológicos se encuentran en los Rasgos 3, 7, 8 y 10, aunque se detectó una dispersión generalizada y escasa de semillas en toda la planta (11,4\% del total). Todas se encuentran carbonizadas, algunas están fragmentadas y predominan las identificadas como maíz (Zea sp.), en menor cantidad, posibles semillas de quínoa (Schinus sp.) (en la planta general y el Rasgo 7) y algarrobo (Prosopis sp.) (Rasgos 1, 3,4).

Los resultados del análisis de carporrestos concuerdan con los datos obtenidos a partir del estudio de microrrestos en un fragmento cerámico recuperado en una de las casas semisubterráneas (Rasgo 3), donde se detectaron granos de almidón de Zea mays y de Prosopis sp. (PrietoOlavarría, Chiavazza y Musaubach, 2019).

El análisis antracológico incluyó 373 carbones del Rasgo 5. La fragmentación (frag./ Vol.= $3.01 \mathrm{y}$ Vol. $>$ / Vol. $\leq 3 \mathrm{~mm}=0.01$ ), así como las condiciones de conservación, permitió observar caracteres diagnósticos, muchas veces con dificultad, pero con un bajo número de fragmentos no identificados (NI). Se verificó una riqueza de 20 taxones y una diversidad de 2.3 (Shannon H). Por su parte, el índice de dominancia fue de 0.1626 (Dominance_D) y el de Simpson 0.8373 (Simpson_1-D) (Tabla 3). Se definió que los géneros Acacia, Prosopis y Larrea, seguidos por Bulnesia y Geoffroea, resultaron los más frecuentes en la muestra, lo que podría indicar que 
estos fueron seleccionados como materia prima para estructuras o como leña. La muestra de Aff. Asteraceae no se incluyó, ya que correspondería a un elemento único, que si bien se halló en una concentración de carbones (rasgo 5), no es posible adscribirla a postes y estructuras, ya que estos usos de la leña se distinguen por su alta riqueza y diversidad.

Tabla 3. Taxones identificados mediante el análisis de carbón para el sitio MB.

\begin{tabular}{|c|c|c|c|c|}
\hline Taxón & Nombre común & $N^{\circ}$ Frag & Vol (ml) & $\%$ Vol \\
\hline Salix humboldtiana & Sauce & 2 & 2 & 1.02 \\
\hline Schinus sp. & Molle & 7 & 2.5 & 1.28 \\
\hline Bulnesia retama & Retamo & 42 & 25 & 12.79 \\
\hline Aff. Acacia/Prosopis & Caldén/algarrobo & 75 & 45.4 & 23.23 \\
\hline Aff. Acacia spp. & Aromo/garabato & 21 & 34.4 & 17.60 \\
\hline Aff.Prosopis flexuosa & Algarrobo dulce & 6 & 7 & 3.58 \\
\hline Geoffroea decorticans & Chañar & 47 & 21.1 & 10.80 \\
\hline Fabaceae aff. Parkinsonia & Cina-cina & 2 & 1.5 & 0.77 \\
\hline Larrea sp. & Jarilla & 97 & 39 & 19.96 \\
\hline Aff. Prosopidastrum & - & 1 & 0.3 & 0.15 \\
\hline Aff. Anacardiaceae & - & 1 & 0.4 & 0.20 \\
\hline Asteraceae aff. Tessaria & Pájaro bobo & 1 & 0.3 & 0.15 \\
\hline Aff. Oleaceae & - & 1 & 0.6 & 0.31 \\
\hline Aff, Atriplex/Allenrolfea & Zampa/jume & 7 & 2.3 & 1.18 \\
\hline Lycium chilensis & Llaullín & 4 & 1.3 & 0.67 \\
\hline Aff. Asteraceae ${ }^{*}$ & - & 33 & 45 & - \\
\hline Aff. Proustia cuneifolia & Altepe & 1 & 1.5 & 0.77 \\
\hline Aff. Caesalpinia Gilliesii & Lagaña de perro & 5 & 2.2 & 1.13 \\
\hline Taxón 2 & - & 2 & 1.8 & 0.92 \\
\hline Taxón 5 & - & 1 & 0.4 & 0.20 \\
\hline Taxón 6 & - & 1 & 0.2 & 0.10 \\
\hline NI & - & 16 & 6.2 & 3.17 \\
\hline Totales & & 373 & 240.4 & 100 \\
\hline
\end{tabular}

\section{Análisis de tecnología lítica}

El total del material lítico excavado en MB asciende a 609 restos. El 0,8\% (5 elementos $=61$ g., en 1 rasgo en $7.06 \mathrm{~m}^{2}$ ) se recuperó en el contexto más tardío y el 99,2\%, en los rasgos más tempranos y profundos (598 elementos $=14839.5$ g., en 14 rasgos, $113 \mathrm{~m}^{2}$ ). En este segundo componente, se identificaron 12 tipos de materias primas y otras indeterminadas. Predominan las materias primas locales, disponibles en el piedemonte oriental de precordillera e incluso en 
los márgenes de los cañadones aluvionales asociados al sitio. ${ }^{2}$ También se hallaron silíceas de precordillera y exóticas como combarbalita, proveniente del Norte Chico de Chile. Las calidades para tallar de este conjunto son entre media y baja. Considerando cantidades o pesos, la relevancia de las materias primas varía. Se confirma la preponderancia de cuarcita de disponibilidad local, aunque gravita menos su peso (42\%) que su cantidad (56,1\%). Las tendencias varían: la riolita pasa de un segundo lugar en cantidad (19\%) a un cuarto lugar en peso $(6,8 \%)$; los basaltos, que están en tercer lugar según cantidad (6,8\%), pasan a un segundo lugar considerando el peso (18\%). Las materias primas indeterminadas también presentan diferencias al considerar cantidad $3,8 \%$ y el peso $12 \%$ (Figura $3 \mathrm{~A}$ ).

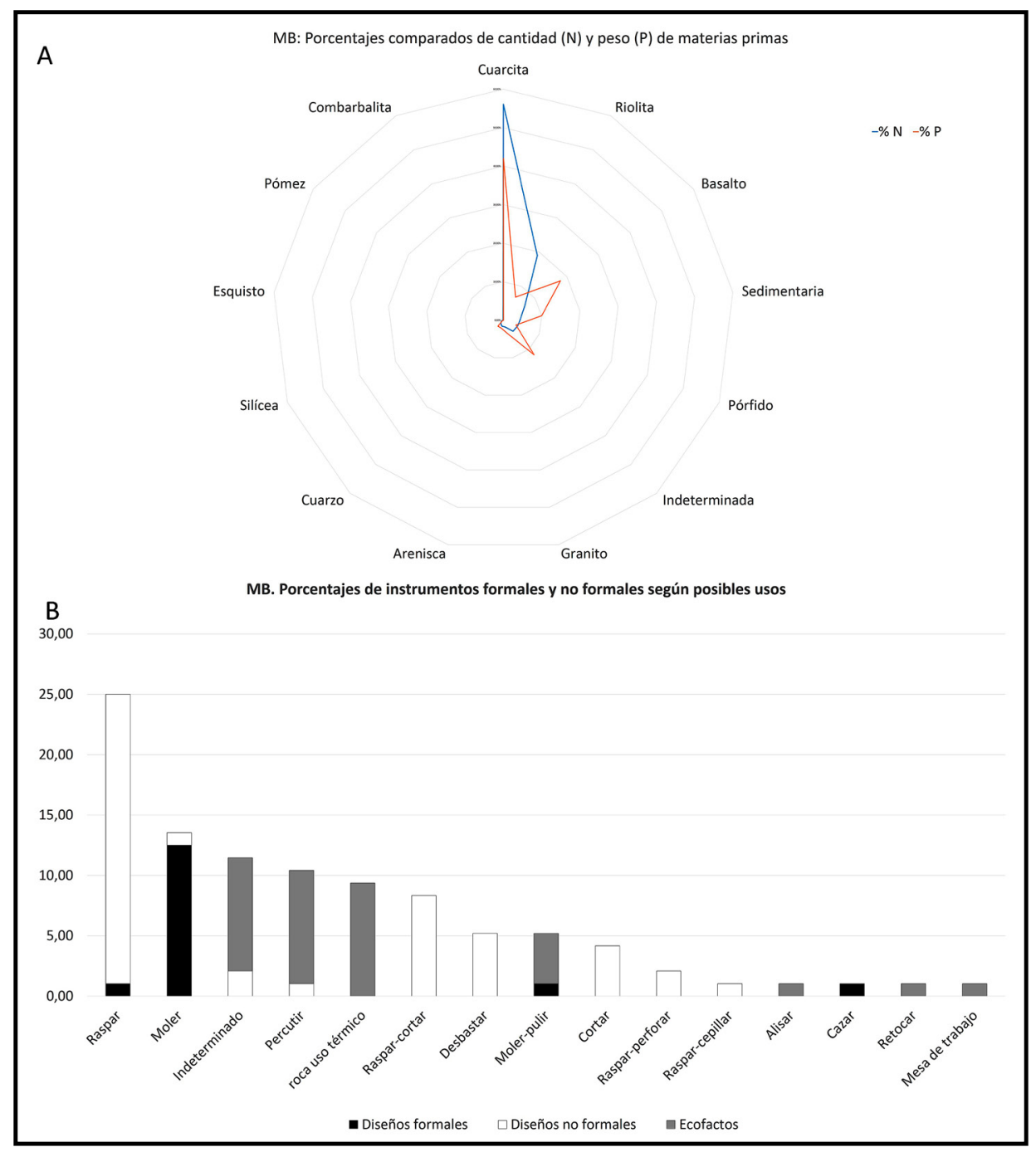

Figura 3. A) Materias primas líticas. Porcentajes comparados según cantidad y peso;

B) Porcentaje de instrumentos según diseño e hipotéticos usos.

2 Los canales aluvionales están impermeabilizados en su tramo urbano, pero hacia el oeste aún pueden observarse las rocas disponibles (Chiavazza et al., 2008). 
Para calcular la diversidad se consideraron los tipos generales de materias primas y su frecuencia, aplicando los índices de diversidad y dominancia a las cantidades. El resultado obtenido de la aplicación del índice de Shannon-H da cuenta de baja diversidad (por debajo de 2), aspecto que se corrobora por el valor intermedio del índice de diversidad de Simpson (Tabla 4). La tendencia a la homogeneidad se expresa en el volumen dominante de cuarcitas de disponibilidad local.

Tabla 4. Cálculos aplicados a las materias primas líticas correspondientes a los niveles más tempranos.

\begin{tabular}{|c|c|c|c|c|c|}
\hline N Lítico & Indeterminados & cálculos & D Simpson & Simpson 1-D & Shannon-H \\
\hline 598 & 22 & 576 & 0.3892807 & 0.6107193 & 1.36 \\
\hline
\end{tabular}

En términos tecnológicos, se observa gran parte de las etapas del proceso de reducción, ya que no se recuperaron restos de reactivación, por lo cual, se infiere que no se desarrollaron actividades de mantenimiento y reparación de instrumentos en el sitio. Esto se correlaciona también con una baja cantidad de restos de adelgazamiento secundario y retoque. Predomina el adelgazamiento primario, la reducción inicial y la preparación del núcleo (Tabla 5).

El índice de desecho/instrumento arroja 5.2 productos por cada instrumento. Entre instrumentos y ecofactos suman el $16 \%$ de los restos líticos, un porcentaje alto en el contexto regional. Los descartes ascienden al $11 \%$ y se mantienen en los promedios regionales. Los instrumentos predominan sin diseños formales y la cantidad de ecofactos líticos es significativa. Los instrumentos responden a usos expeditivos de filos naturales o con retoques marginales y muescas o cantos rodados pequeños usados posiblemente como alisadores (Figura 4A).

Los instrumentos con mayor trabajo de talla muestran retoques unifaciales, poco extendidos, sobre nódulos grandes y con mucha reserva de corteza. No se consideran estandarizados o resultantes de un diseño formal estricto, pero se evidencia la búsqueda de un prototipo vinculado con acciones de corte sobre materiales duros (p.e., madera). Un artefacto diseńado corresponde a un gancho de propulsor elaborado sobre una materia prima exótica como la combarbalita (Figura 4B). Otros instrumentos que responden a un patrón diseñado son las manos de moler, que a través de desgaste fueron generando piezas estandarizadas por selección en relación a su función (rocas redondas, aplanadas y de tamaño anatómicamente apto para la mano) (Figura 4C). 
Tabla 5. Frecuencia de productos asociados a etapas del proceso de reducción lítico por cada rasgo excavado.

\begin{tabular}{|c|c|c|c|c|c|c|c|c|c|c|}
\hline Rasgos & $\frac{.00}{\frac{0}{0}}$ & $\frac{\stackrel{8}{0}}{2}$ & 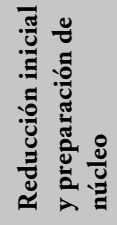 & 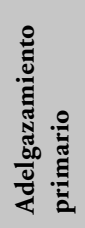 & 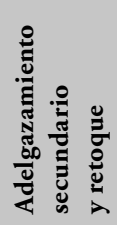 & 苞 & है & 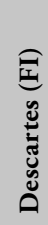 & $\frac{\mathscr{U}}{\tilde{\pi}}$ & సี \\
\hline Rasgo 0 & 0 & 0 & 0 & 0 & 1 & 0 & 0 & 0 & 0 & 1 \\
\hline Rasgo 1 & 0 & 0 & 9 & 12 & 2 & 0 & 9 & 3 & 0 & 35 \\
\hline Rasgo 2 & 0 & 0 & 0 & 0 & 0 & 0 & 0 & 0 & 0 & 0 \\
\hline Rasgo 3 & 4 & 2 & 53 & 58 & 19 & 0 & 21 & 23 & 11 & 191 \\
\hline Rasgo 4 & 5 & 1 & 5 & 13 & 5 & 0 & 1 & 3 & 5 & 38 \\
\hline Rasgo 5 & 4 & 2 & 6 & 5 & 2 & 0 & 6 & 0 & 7 & 32 \\
\hline Rasgo 6 & 0 & 2 & 4 & 1 & 1 & 0 & 2 & 0 & 2 & 12 \\
\hline Rasgo 7 & 5 & 0 & 37 & 33 & 15 & 0 & 13 & 16 & 4 & 123 \\
\hline Rasgo 8 & 0 & 0 & 1 & 0 & 0 & 0 & 1 & 0 & 0 & 2 \\
\hline Rasgo 9 & 1 & 0 & 5 & 5 & 4 & 0 & 2 & 1 & 0 & 18 \\
\hline Rasgo 10 & 1 & 0 & 8 & 7 & 7 & 0 & 0 & 8 & 1 & 32 \\
\hline Rasgo 11 & 0 & 0 & 2 & 3 & 0 & 0 & 0 & 1 & 0 & 6 \\
\hline Rasgo 12 & 0 & 0 & 0 & 0 & 0 & 0 & 0 & 0 & 0 & 0 \\
\hline Rasgo 13 & 0 & 0 & 0 & 1 & 0 & 0 & 0 & 0 & 0 & 1 \\
\hline Rasgo 14 & 0 & 0 & 10 & 21 & 15 & 0 & 1 & 7 & 0 & 54 \\
\hline $\begin{array}{l}\text { Planta general sin } \\
\text { rasgo }\end{array}$ & 1 & 1 & 12 & 18 & 6 & & 6 & 5 & 4 & 53 \\
\hline $\begin{array}{l}\text { Totales } \\
\text { (nivel temprano) }\end{array}$ & 21 & 8 & 152 & 177 & 77 & 0 & 62 & 67 & 34 & 598 \\
\hline $\begin{array}{l}\text { Niveles tardíos entre } \\
180 \text { y } 200 \mathrm{~cm} \text { prof }\end{array}$ & 0 & 1 & 1 & 1 & 1 & 0 & 0 & 1 & 0 & 5 \\
\hline Total MB & 21 & 9 & 153 & 178 & 78 & $\mathbf{0}$ & 68 & 68 & 34 & 609 \\
\hline
\end{tabular}

De acuerdo al enfoque tipológico, se diferencian preliminarmente actividades en las que se involucraron los instrumentos y se observa el predominio de acciones vinculadas al procesamiento: raspar, cortar, moler, entre otras (Figura 3B).

Un aspecto significativo está relacionado con la ausencia de puntas de proyectil, lo que constituye una tendencia recurrente en las ocupaciones prehispánicas excavadas en el sustrato de la ciudad (Chiavazza et al., 2019). 


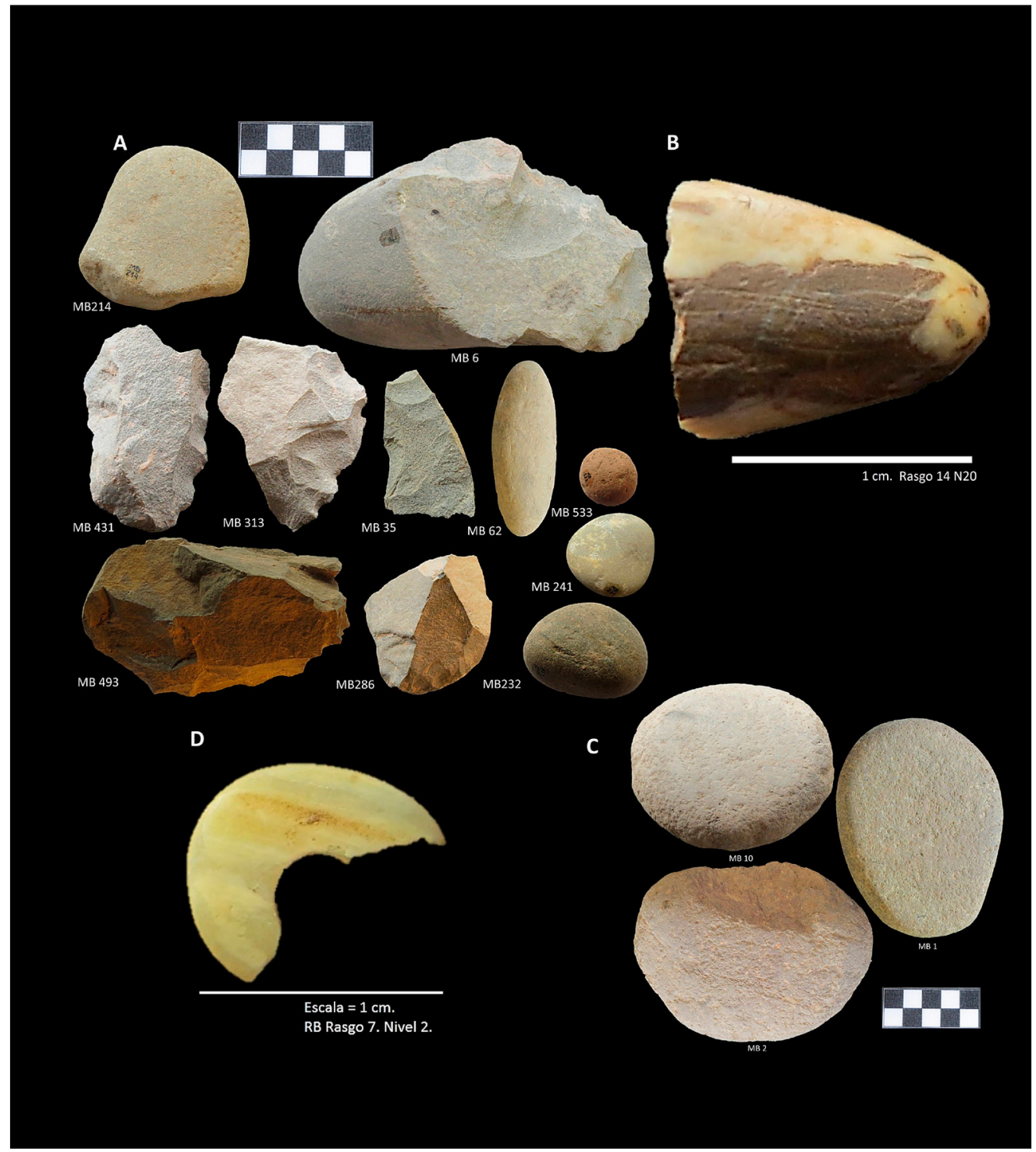

Figura 4. Elementos lítico y malacológicos (diferentes escalas). A) Instrumentos y ecofactos; B) Gancho de propulsor; C) Manos de moler; D) Elemento malacológico: cuenta de collar.

\section{Análisis zooarqueológico}

Los resultados de los estudios zooarqueológicos del sitio han sido presentados de forma general (Chiavazza, 2013, 2014) y se profundizaron en el caso de los micromamíferos (López, 2018). Se realizaron identificaciones taxonómicas a nivel de especie y género a partir de las cuales se calcularon NISP y NMI. Los restos, generalmente astillados y no identificables, se tipificaron como macro y microfauna y se dividieron según tamaño y estado de termoalteración. Por su parte, sobre aquellos identificables anatómicamente y en algún nivel taxonómico, se realizaron cálculos de NISP, MNI como base para calcular índices de diversidad y homogeneidad (Tabla 6). 
Tabla 6. Restos arqueofaunísticos según frecuencias de NISP y MNI (N y \%).

\begin{tabular}{|c|c|c|c|c|}
\hline Taxa & MNI & $\%$ & NISP & $\%$ \\
\hline \multicolumn{5}{|l|}{ Caviidae } \\
\hline Caviidae indet & 3 & 6.25 & 16 & 4.92 \\
\hline Galea leucoblephara & 3 & 6.25 & 11 & 3.38 \\
\hline Microcavia australis & 6 & 12.50 & 17 & 5.23 \\
\hline Ctenomyidae & & 0.00 & & 0.00 \\
\hline Ctenomys sp. & 4 & 8.33 & 38 & 11.69 \\
\hline Cricetidae & & 0.00 & & 0.00 \\
\hline Cricetidae indet & 2 & 4.17 & 23 & 7.08 \\
\hline Akodon dolores & 2 & 4.17 & 4 & 1.23 \\
\hline Eligmodontia sp. & 1 & 2.08 & 1 & 0.31 \\
\hline Graomys griseoflavus & 3 & 6.25 & 7 & 2.15 \\
\hline Holochilus lagigliai & 1 & 2.08 & 2 & 0.62 \\
\hline Ave & & 0.00 & & 0.00 \\
\hline Ave indeterminada peq-med & 5 & 10.42 & 80 & 24.62 \\
\hline Camelidae & & 0.00 & & 0.00 \\
\hline Lama sp & 2 & 4.17 & 12 & 3.69 \\
\hline Dasypodidae & & 0.00 & & 0.00 \\
\hline Zaedyus pichiy & 2 & 4.17 & 20 & 6.15 \\
\hline Armadillo ind. (1) & 1 & 2.08 & 1 & 0.31 \\
\hline Mamífero ind. $(1-10 \mathrm{~kg})(1)$ & 2 & 4.17 & 19 & 5.85 \\
\hline Pez & & 0.00 & & 0.00 \\
\hline Percichtys trucha & 2 & 4.17 & 33 & 10.15 \\
\hline Pez ind. (1) & 4 & 8.33 & 29 & 8.92 \\
\hline Reptilia & & 0.00 & & 0.00 \\
\hline Reptil ind. & 5 & 10.42 & 12 & 3.69 \\
\hline Totales & 48 & 100.00 & 325 & 100.00 \\
\hline
\end{tabular}

Los cálculos se realizaron excluyendo armadillo, mamífero y pez sin determinaciones específicas, lo que arrojó una riqueza específica de 14 taxa y 41 individuos y se usó como base para calcular los índices de diversidad. El índice de dominancia (D) es bajo, mientras que la diversidad (Simpson 1-D) indicada es alta, lo que se corrobora con el índice de Shannon superior a 2 (Tabla 7).

El análisis de la fauna por medio de los restos óseos indica presas de porte pequeño, tanto en lo referido a aves y peces como a mamíferos. No obstante, existen evidencias de Camelidae, incluso con marcas de procesamiento. 
Tabla 7. Índices de diversidad y dominancia calculados para arqueofaunas de MB.

\begin{tabular}{|c|c|c|c|c|}
\hline Taxa & Individuos & Dominancia D & Simpson 1-D & Shannon-H \\
\hline 14 & 41 & 0.08983 & 0.9102 & 2.513 \\
\hline
\end{tabular}

En cuanto al procesamiento, se detectaron astillajes y evidencias de marcas de corte, así como también alteraciones por calor: quemados, calcinados y tostados. Destaca la existencia de huesos de micromamíferos con evidencia de uso humano y que incluye a Holochilus lagigliai, especie actualmente extinta, propia de los ambientes de humedal. Los huesos de camélidos, y especialmente de aves, muestran marcas de corte y procesamiento que indican mayor aprovechamiento, por ejemplo, extracción de médula ósea (Figura 5).

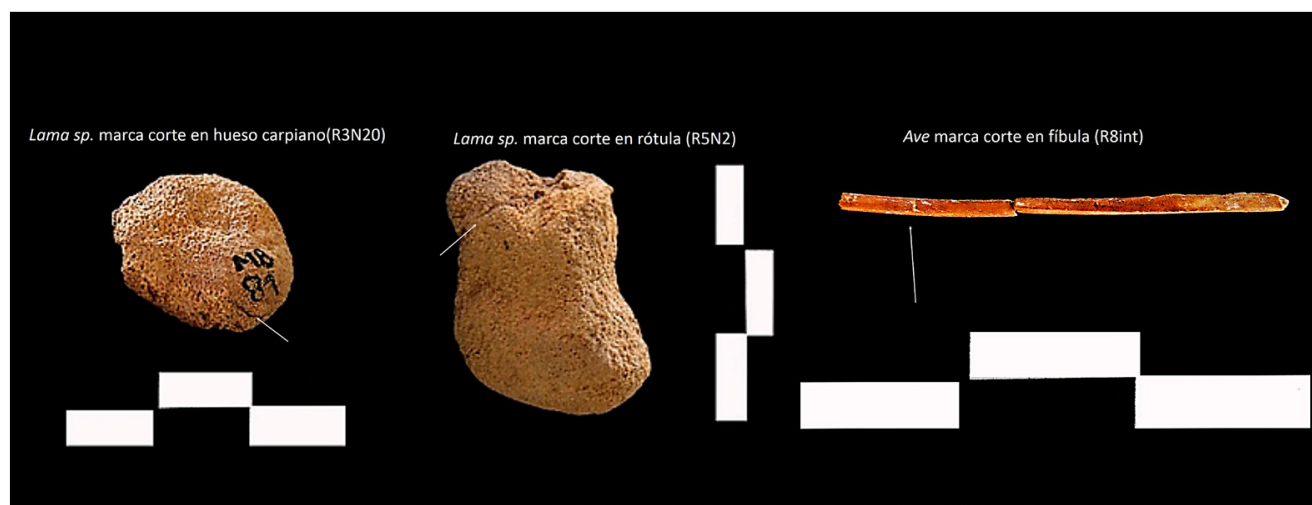

Ave marca corte en tibio tarso (R3N5

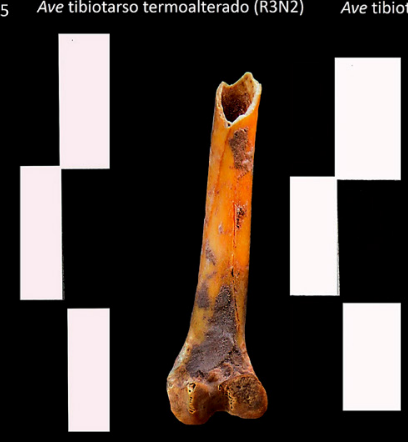

Holochilus lagigliai tost<ado (R3N6)
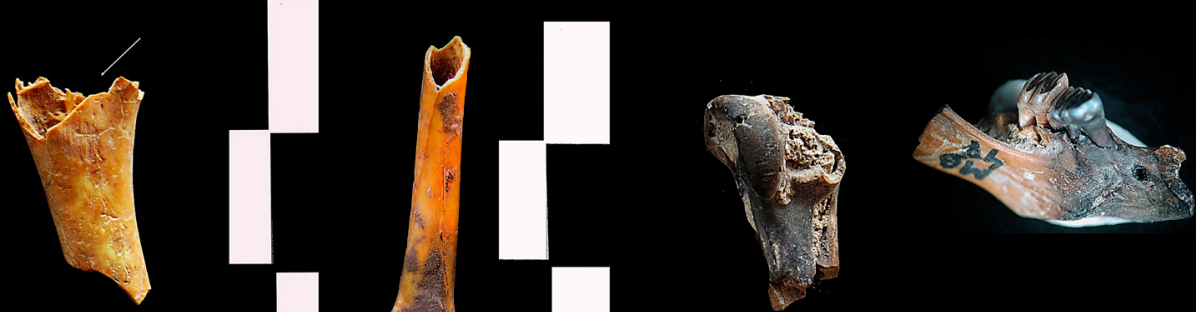

Ave marca de diente en fibula (R3NG)
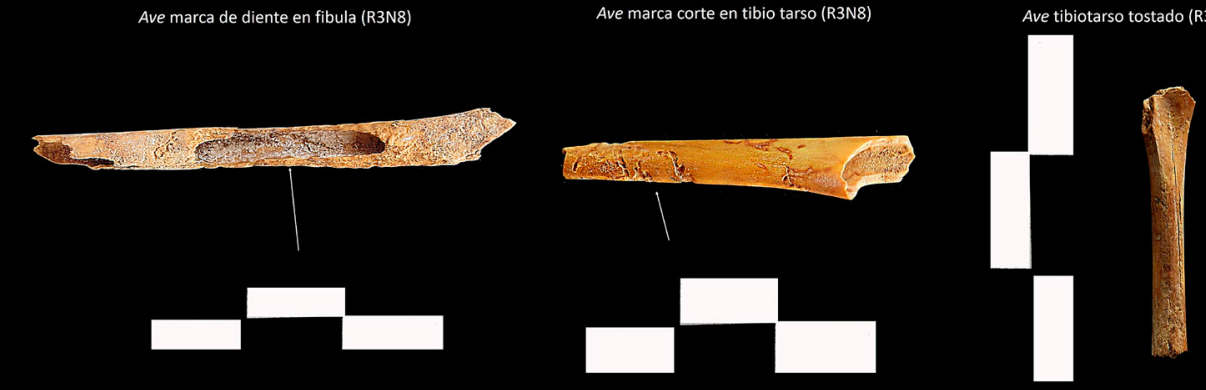

Figura 5. Restos óseos de MB con marcas y huellas. 
Se observó poca cantidad de astillas $(\mathrm{N}=562)$ si se compara en el contexto regional más amplio, como los sitios de precordillera y planicie noreste, Rincón de los Helados y Tulumaya (Chiavazza, 2010). Las mismas se distribuyen diferencialmente en cuanto a cantidades según los rasgos excavados (Figura 6).

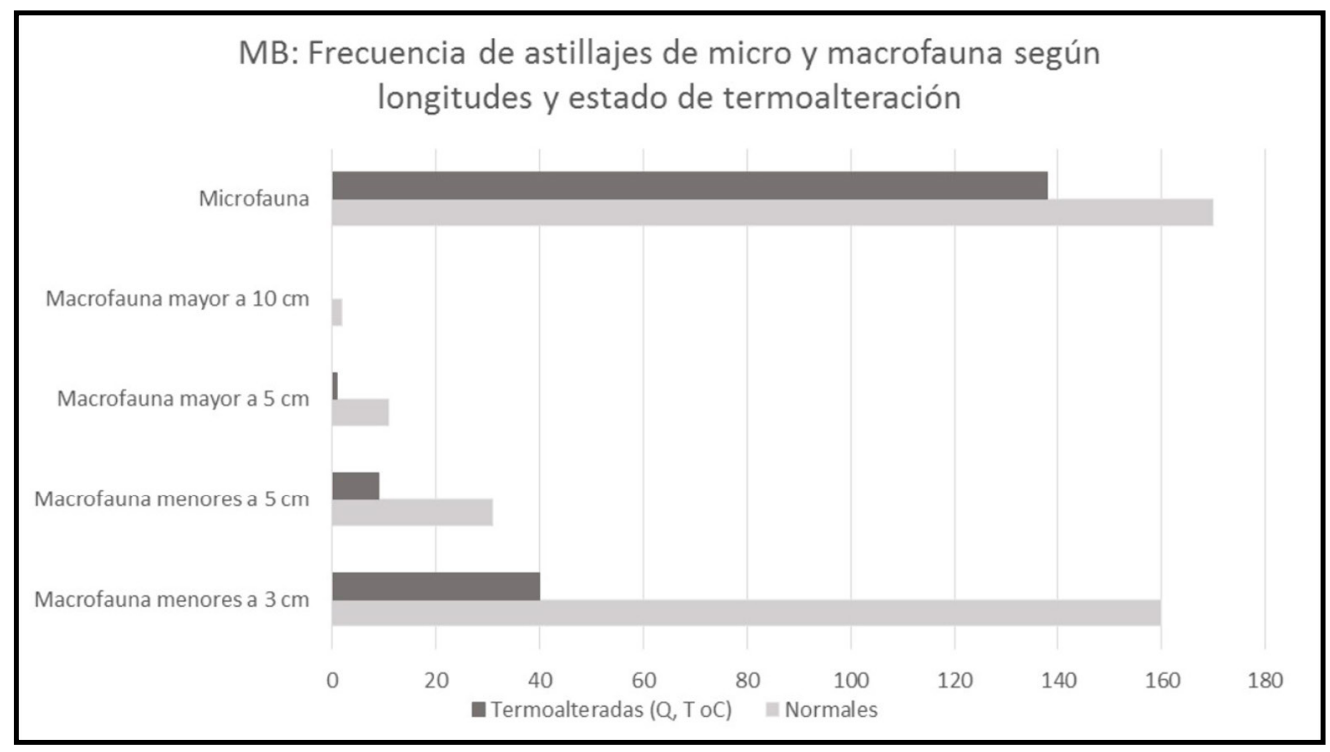

Figura 6. Frecuencias de astillas de micro y macrofauna según estado y tamaño.

Comparativamente, observamos que es mayor la cantidad de astillas de microfauna (54\%) que de macrofauna (46\%). A su vez, dentro de cada conjunto, las termoalteradas (quemadas, tostadas y/o calcinadas) muestran también porcentajes diferenciados: $8,9 \%$ en la macrofauna; $34,5 \%$ en la microfauna. Las astillas sin termoalteraciones evidentes ascienden al 36,2\% en el caso de macrofauna y $30,2 \%$ de la microfauna. Los rangos de longitud indican que la totalidad de las astillas correspondientes a microfauna son inferiores a los $3 \mathrm{~cm}$, lo que indicaría mayor integridad, dado que estos huesos no suelen superar estas dimensiones. En tanto los de fauna de mayor porte muestran astillamiento intenso, dado que las longitudes de menos de $3 \mathrm{~cm}$ predominan con $35,5 \%$, seguidas en orden decreciente de representatividad por: las mayores a $3 \mathrm{~cm}$ y menores a $5 \mathrm{~cm}$, con el 7,1\%; las mayores a $5 \mathrm{~cm}$ y menores a $10 \mathrm{~cm}$, con el $2 \%$; las mayores a $10 \mathrm{~cm}$ de longitud, con el 0,3\% (Figura 7).

El único elemento zooarqueológico que muestra evidencias de uso ornamental es un resto malacológico formatizado como cuenta de collar (Figura 4D). 


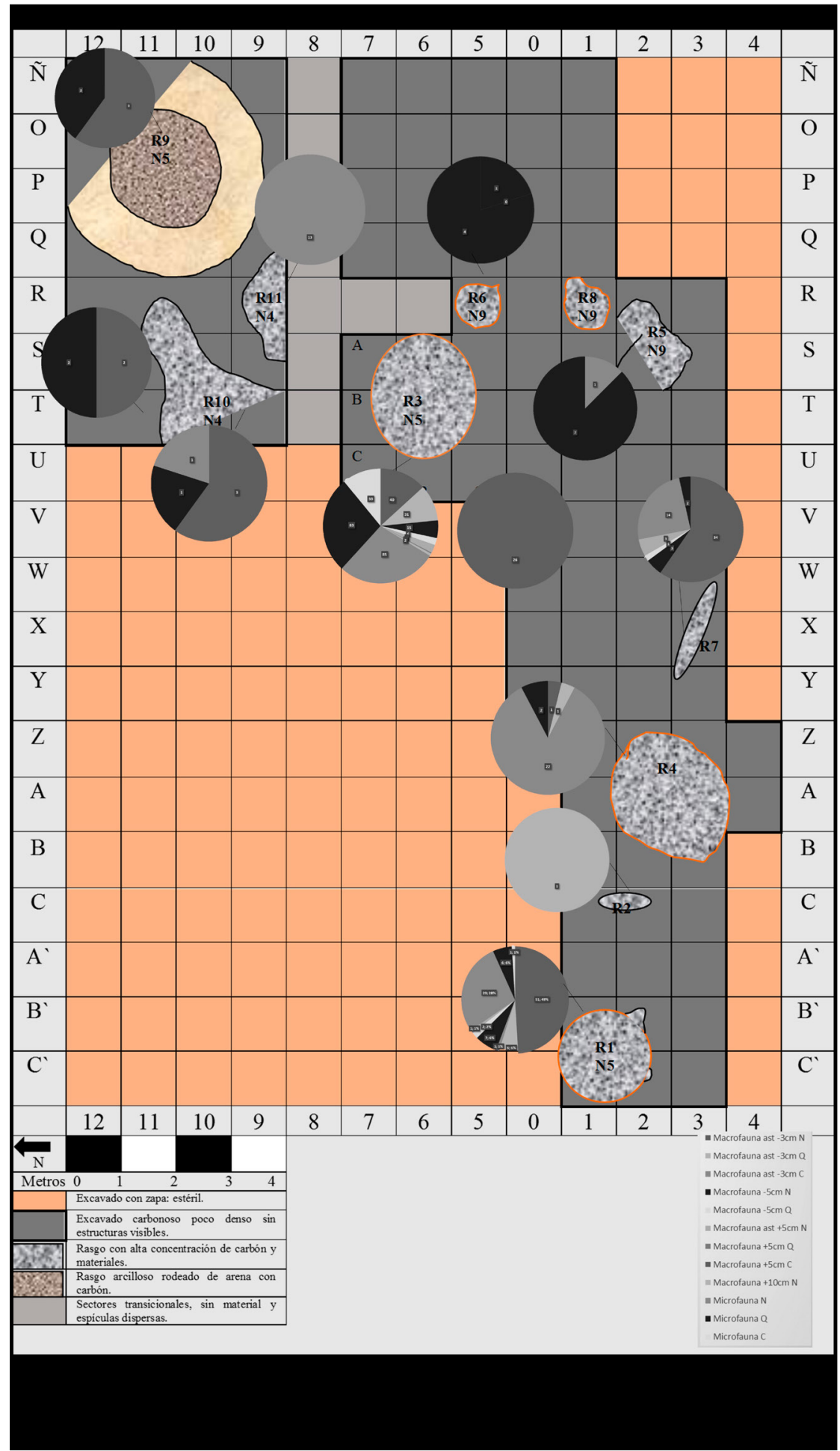

Figura 7. Gráficos de cantidades de astillas de macro y microfauna según longitud y estado, ubicados en relación a los rasgos excavados en planta. 


\section{Análisis cerámico}

En los rasgos más profundos, ubicados aproximadamente a $4 \mathrm{~m}$ de profundidad, se recuperó un total de 195 fragmentos cerámicos, los que ensamblados sumaron 190 tiestos. El Rasgo 3 seguido del Rasgo 1, correspondientes a casas semisubterráneas, son los que poseen mayor cantidad de fragmentos (Tabla 8). Considerando los fechados obtenidos en el Rasgo 3 de aproximadamente cal 2100 años AP (Tabla 2), la cerámica presente en los niveles más profundos se integra a la evidencia alfarera más temprana del COA (Bárcena, 1998; Chiavazza, 2005; Marsh, 2017). El conjunto cerámico presenta características generales compartidas, ya que todos los fragmentos presentan superficies de tonalidades grises y marrones, predominan los tratamientos de superficie alisados (99\%) por sobre los pulidos (1\%), y son mayoritarias las cocciones reductoras $(83 \%)$ por sobre las oxidantes $(13 \%)$ y las oxidantes incompletas $(4 \%)$.

Para el análisis de forma, fueron clasificadas las diversas secciones representadas en el conjunto: borde, unión borde-cuello, unión borde-cuerpo, unión cuello-cuerpo, cuerpo, asa, base. Para aproximarse a las formas representadas, se realizó el análisis de las secciones diagnósticas (unión borde-cuello, unión borde-cuerpo, unión cuello-cuerpo), basado en la detección de puntos característicos (Shepard, 1956). Se definió la presencia de clases estructurales de forma (formas no restringidas y formas restringidas) (Shepard, 1956, p. 226), aunque solo se pudo hacer en pocos casos, ya que el conjunto se caracteriza por el pequeño tamaño de los restos y por la mayoritaria presencia de secciones de cuerpo (formas indeterminadas). Esta dificultad en la definición formal se debe, en parte, a que no existen en la región colecciones de vasijas completas o ensambladas de cerámica temprana, las que permitirían inferir con mayor precisión la morfología de los conjuntos fragmentarios.

Debido a la necesidad de analizar en mayor detalle la morfología cerámica, se identificaron las clases estructurales en los casos que fue posible y se trabajó con los fragmentos en los que se reconoció el punto característico: forma no restringida (clase estructural); posible forma no restringida representada por unión borde-cuerpo cuya abertura está marcada por una tangente de punto final vertical o inclinada hacia fuera (Shepard, 1956, p. 229); forma con punto tangencial vertical correspondiente a unión borde-cuello y cuello-cuerpo (no se puede inferir la clase estructural); formas indeterminadas representadas por secciones de cuerpo (Tabla 8).

Entre los fragmentos de mayor tamaño (algunos ensamblados), destaca una vasija no restringida asimétrica, que podría corresponder a una forma fitomorfa (curcubitácea) (Figura 8A), y una base de vasija que evidencia proceso de reutilización y mantenimiento, ya que el borde está canteado y define una forma no restringida (Figura 8B). 
Tabla 8. Sitio Memorial de la Bandera.

Cantidad de fragmentos ensamblados y formas por rasgo de procedencia.

\begin{tabular}{|c|c|c|c|c|c|c|}
\hline & $\begin{array}{c}\text { Forma } \\
\text { no } \\
\text { restringida }\end{array}$ & $\begin{array}{l}\text { Probables } \\
\text { formas no } \\
\text { restringidas }\end{array}$ & $\begin{array}{c}\text { Formas } \\
\text { con punto } \\
\text { tangencial } \\
\text { vertical }\end{array}$ & $\begin{array}{c}\text { Formas } \\
\text { indeterminadas }\end{array}$ & $\begin{array}{l}\text { Otras } \\
\text { formas }\end{array}$ & Total \\
\hline Rasgo 1 & & - & 1 & 25 & $\begin{array}{c}2 \\
\text { pulidor y } \\
\text { apéndice }\end{array}$ & 28 \\
\hline Rasgo 2 & & - & - & 6 & - & 6 \\
\hline Rasgo 3 & 1 & 7 & 12 & 61 & - & 81 \\
\hline Rasgo 4 & & 2 & 1 & 9 & - & 12 \\
\hline Rasgo 5 & & - & 1 & 11 & - & 12 \\
\hline Rasgo 6 & & - & 1 & 3 & - & 4 \\
\hline Rasgo 7 & & 2 & 2 & 11 & - & 15 \\
\hline Rasgo 9 & & 1 & 2 & 8 & - & 11 \\
\hline Rasgo 10 & & - & - & 1 & - & 1 \\
\hline Rasgo 11 & & - & 2 & - & - & 2 \\
\hline Rasgo 14 & & - & - & 13 & - & 13 \\
\hline Sondeo 5 & & - & - & 1 & - & 1 \\
\hline Sondeo 8 & & - & - & 2 & & 2 \\
\hline Bajo Rasgo 11 & & - & - & 2 & - & 2 \\
\hline Total & 1 & 12 & 22 & 153 & 2 & 190 \\
\hline
\end{tabular}




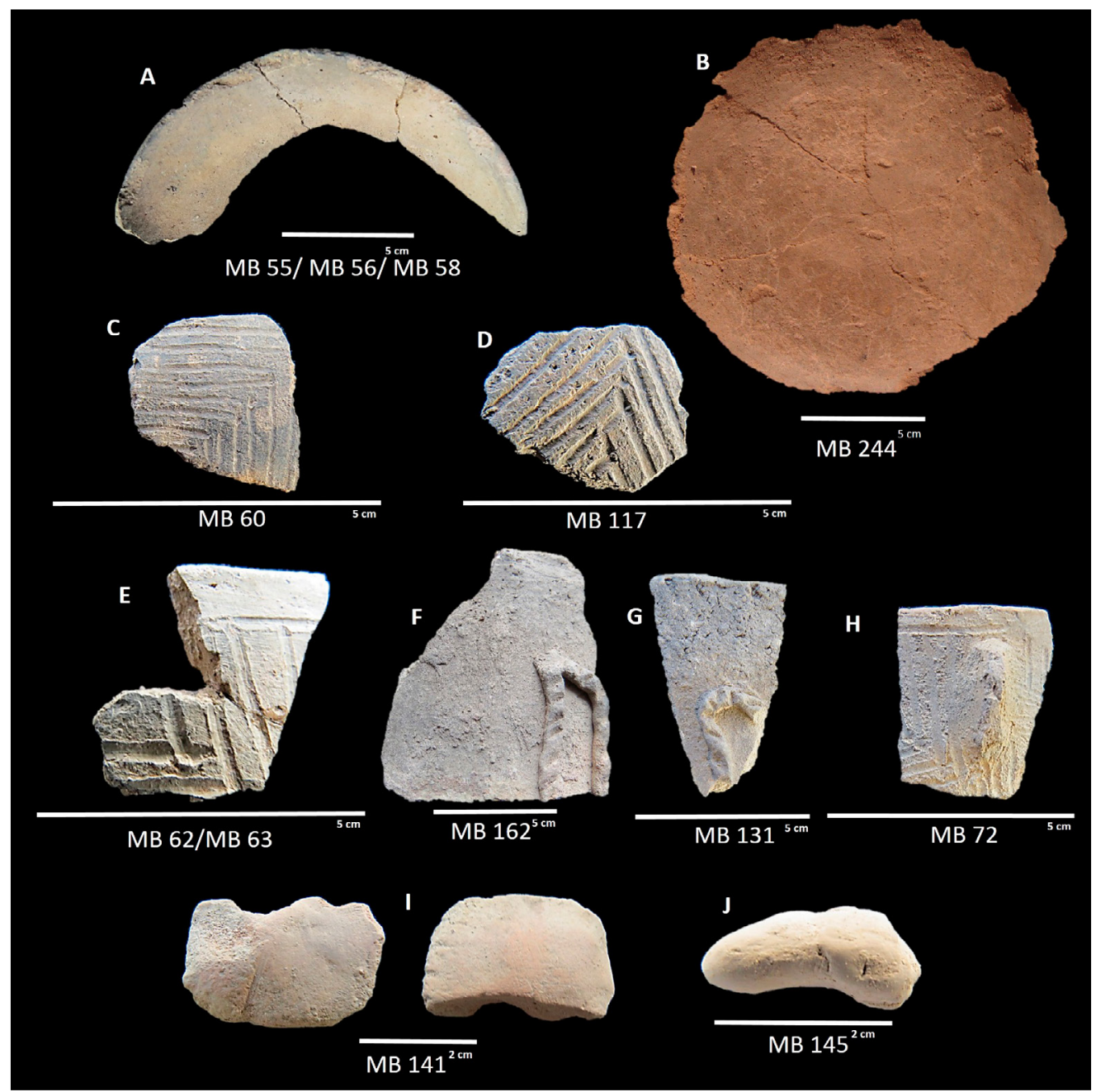

Figura 8. Formas de vasijas y artefactos de cerámica del sitio MB. A) Forma no restringida, posiblemente fitomorfa (MB55, MB56, MB58); B) Fragmento de vasija con bordes canteados (MB244) fotografiado in situ; C) y D) Fragmentos con motivo de chevrón (MB60 y MB117); E) Unión borde-cuello de vasija con decoración incisa (MB62 y MB63); F) Fragmento borde-cuello con decoración por pastillaje inciso (MB162); G) Fragmento borde-cuello con decoración por pastillaje inciso (MB131); H) Fragmento de borde-cuello con decoración incisa y mamelón modelado (MB72); I) Pieza usada posiblemente como afilador (MB141); J) Pequeño apéndice (MB145). MB y número= sigla del fragmento. 
Veintidós fragmentos presentan algún tipo de decoración (Tabla 9). Predominan las incisas con motivos de líneas, entre los que se distingue el chevrón (Figura 8C y 8D). Destacan cuatro fragmentos de borde-cuello (posibles formas no restringidas): uno presenta motivo lineal inciso (Figura 8E); dos tienen decoración de patillaje incisos (Figura 8F y 8G); uno presenta chevrón inciso y mamelón modelado (Figura $8 \mathrm{H}$ ). Un atributo que se observa entre las incisiones, es el desplazamiento de material (Figura $8 \mathrm{D}$ y $8 \mathrm{E}$ ), lo que indicaría que fueron realizadas con la pasta fresca (Rye, 1981; Rice, 1987).

Tabla 9. Sitio Memorial de la Bandera.

Fragmentos decorados y técnicas de decoración por rasgo de procedencia.

\begin{tabular}{|c|c|c|c|c|c|c|}
\hline & $\begin{array}{l}\text { Inciso } \\
\text { Probable } \\
\text { Forma no } \\
\text { restringida }\end{array}$ & 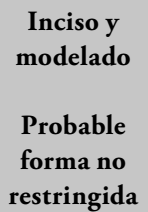 & $\begin{array}{l}\text { Pastillaje e } \\
\text { inciso } \\
\text { Probable } \\
\text { forma no } \\
\text { restringida }\end{array}$ & $\begin{array}{c}\text { Inciso } \\
\text { Forma con } \\
\text { punto tangencial } \\
\text { vertical }\end{array}$ & $\begin{array}{c}\text { Inciso } \\
\text { Forma } \\
\text { Indeterminada }\end{array}$ & Total \\
\hline Rasgo 1 & - & & - & - & 2 & 2 \\
\hline Rasgo 2 & - & & - & - & 2 & 2 \\
\hline Rasgo 3 & - & & - & 3 & 6 & 9 \\
\hline Rasgo 4 & - & 1 & - & - & - & 1 \\
\hline Rasgo 7 & 1 & & 1 & - & 1 & 3 \\
\hline Rasgo 9 & - & & - & - & 3 & 3 \\
\hline Rasgo 11 & - & & 1 & - & - & 1 \\
\hline Rasgo 14 & - & - & - & - & 1 & 1 \\
\hline Total & 1 & 1 & 2 & 3 & 17 & 22 \\
\hline
\end{tabular}

Respecto a las huellas de uso, solo fue posible detectar las ocasionadas por termoalteración, presentes en el $67 \%$ de los fragmentos (Tabla 10). Todos los tiestos unión cuello-cuerpo y unión borde-cuello (forma con punto tangencial vertical) presentan huellas por termoalteración. La presencia de hollín grueso y muy adherido, que observamos en 31 casos (16\%), indicaría que estas vasijas fueron usadas para hervir alimentos (sensu Skibo, 2015). 
Tabla 10. Sitio Memorial de la Bandera.

Cantidad de fragmentos con huellas por termoalteración: huellas en general; detalle de huellas de hollín.

\begin{tabular}{|l|c|c|}
\hline & $\begin{array}{c}\text { Huellas por } \\
\text { termoalteración } \\
\text { (ahumado con o sin hollín) }\end{array}$ & Huellas de hollín \\
\hline Rasgo 1 & 21 & 1 \\
\hline Rasgo 2 & 5 & 15 \\
\hline Rasgo 3 & 51 & 3 \\
\hline Rasgo 4 & 8 & 2 \\
\hline Rasgo 5 & 12 & - \\
\hline Rasgo 6 & 4 & - \\
\hline Rasgo 7 & 7 & - \\
\hline Rasgo 9 & 7 & - \\
\hline Rasgo 10 & 1 & - \\
\hline Rasgo 11 & 2 & - \\
\hline Rasgo 14 & 6 & - \\
\hline Sondeo 5 & 1 & - \\
\hline Sondeo 8 & 126 & - \\
\hline Total & & - \\
\hline
\end{tabular}

Entre otros artefactos se recuperó un posible afilador cerámico (Figura 8I), el que presenta huellas largas producidas por el frotamiento, y una pequeña pieza en forma de apéndice (Figura 8J). Cabe destacar que en todos los rasgos del sitio se encontró materia prima formada por nódulos compactos de arcilla mezclados con arena.

Como se desprende de este análisis preliminar, la cerámica del sitio presenta, a grandes rasgos, atributos compartidos en relación al color y tratamiento de superficie, la cocción y la presencia de huellas por termoalteración. Destaca que todas las uniones cuello-cuerpo y borde-cuello tienen restos de hollín, por lo que se puede inferir que fueron vasijas usadas para cocinar sobre el fuego. En cuanto a las decoraciones, si bien no son abundantes, la mayoría son incisas y destacan los motivos de chevrón y las decoraciones de pastillaje incisos. Estos atributos decorativos se corresponden con los fragmentos recuperados en contextos con dataciones tempranas en el norte de Mendoza (Bárcena y Roig, 1981-1982; García, 1992; Bárcena, 1998).

\section{Discusión}

La integridad y resolución del registro arqueológico del sitio $\mathrm{MB}$, la cronología y los resultados obtenidos de los análisis de los materiales integran un conjunto valioso de evidencias para analizar la ocupación del piedemonte del norte de Mendoza, sector del que había escasas referencias debido que los restos se encuentran bajo la ciudad de Mendoza. El conjunto de resultados permite abordar los objetivos planteados: caracterizar las ocupaciones humanas más tempranas del piedemonte normendocino durante el Holoceno Tardío y contribuir a la discusión de la evidencia en términos del proceso de intensificación planteado para la región. 
Los fechados permiten plantear que el proceso de ocupación temprana en el sitio MB se inauguró con una casa semisubterránea (Rasgo 3), hace aproximadamente 2100 años y se extendió hasta los 1200 años AP, con reocupaciones de este espacio y la ampliación a otras casas y áreas de actividad: hornillos, rasgos de combustión, hipotéticos canales y una cisterna. Este proceso es acorde con asentamientos de carácter persistente (Schlanger, 1992) y estabilidad ocupacional, aunque no necesariamente de uso permanente, de acuerdo con los resultados obtenidos sobre la cantidad de material, densidades y atributos tales como resolución temporal e integridad. La presencia de tres estructuras habitacionales en el sitio, definidas como casas semisubterráneas, se corresponde con evidencia recuperada anteriormente en el COA y se relaciona con la discusión de estabilidad en el asentamiento. En la faja central del COA, las primeras observaciones de este tipo de casas se hicieron en Paso Las Piedritas en la llanura mendocina, localidad de Palmira (Canals Frau, 1956) y en Quebrada de La Manga, en precordillera (Pablo Sacchero y María del Rosario Prieto, com. pers.). ${ }^{3}$ Las dataciones obtenidas de este tipo de casas en otros sectores de la región se corresponden con las del sitio $\mathrm{MB}$, ya que están entre los ca. 2000 y 1000 años AP. En tierras bajas, en la localidad de Barrancas se halló una estructura de casa semisubterránea que fue datada en torno a los ca. 2100 años AP e interpretada como la más antigua de la región hasta ese momento (Marsh, 2017). Recientemente, las excavaciones en el sitio Casa de San Martín en la ciudad de Mendoza dieron como resultado el hallazgo de este tipo de habitaciones; se las vinculó con los contextos alfareros más tempranos conocidos para el piedemonte y se interpretaron como parte del patrón de asentamiento en torno a los cauces aluvionales (Chiavazza et al. 2019). En la montaña, se encontró evidencia de estas estructuras en el valle precordillerano de Potrerillos (Durán, Cortegoso, Chiavazza, Lagiglia y García, 2002; Cortegoso, 2006; Gasco et al., 2011), donde se planteó que el asentamiento en este tipo de estructuras habría sido permanente entre los 1500-1000 años AP, en el marco de la implementación de nuevas estrategias en el asentamiento, subsistencia y tecnología (Cortegoso, 2006; Gasco et al., 2011).

En el contexto regional descripto, los fechados obtenidos en torno a los 2100 y 1200 años AP ubican al sitio MB entre las ocupaciones más tempranas del piedemonte del norte de Mendoza, en correspondencia con los fechados obtenidos en Barrancas y el Área Fundacional (Bárcena, 1998; Chiavazza, 2005; Marsh, 2017). Estas dataciones indican que el piedemonte se ocupó tardíamente en relación a otros ambientes de la región, ya que el poblamiento humano estuvo en consonancia con los más tempranos registrados en el Cono Sur (Politis, et al., 2001): la puna de la precordillera fue ocupada hace aproximadamente 11.000 años (García, 2003); el piedemonte alto (sobre los $1000 \mathrm{msnm}$ ) y la llanura fueron ocupados hace unos 3000 años (Chiavazza et al., 2008; Chiavazza, 2019).

Los datos obtenidos del análisis de los materiales recuperados en las excavaciones aportan información sobre la movilidad, intercambio, tecnología, condiciones ambientales y prácticas culinarias. Los carporrestos y microrrestos no permiten dilucidar por sí solos si corresponden a remanentes de agricultura inicial o al consumo de productos agrícolas obtenidos por intercambio. En este sentido, la presencia de rasgos relacionados preliminarmente con el manejo del agua (posibles canales y una cisterna) permite pensar hipotéticamente en prácticas de cultivo. Los restos calcinados de semillas de maíz, posible quínoa y algarrobo, sumados a los microrrestos de maíz y algarrobo recuperados de un fragmento cerámica (Prieto-Olavarría et al., 2019), permiten confirmar que estos vegetales fueron consumidos en los contextos domésticos del

3 Excavaciones realizadas en 1997 por Valeria Cortegoso y Horacio Chiavazza permitieron relocalizar el espacio que fue excavado por estos autores en la década del setenta. 
sitio con fines alimentarios o como combustible. En el contexto regional, esta evidencia se corresponde con los macrorrestos recuperados en otros sitios y los estudios isotópicos realizados sobre huesos humanos (García, 1992; Gambier, 1993; Lagiglia, 2001; Gil, Villalba et al., 2014). Por otra parte, el estudio antracológico indica la presencia de vegetación propia del Monte y riqueza taxonómica, aunque no diversidad, por lo cual, comparado con el registro de la Colonia (Prieto y Wuilloud, 1986), permite inferir diferencias en las especies representadas, especialmente debido a la presencia de algarrobos y chañares en los contextos tempranos del sitio MB.

La evidencia zooarqueológica indica la presencia de fauna de tamańo pequeño y sobre todo de especies que ocupan hábitats muy diferentes a los actuales. Restos de pescado y micromamíferos propios de ambientes de humedal indican entornos distintos a los actuales hace 2000 años, aunque dentro de un marco general que tiene características propias de la Provincia Fitogeográfica del Monte. El procesamiento y tratamiento térmico, tanto en huesos reconocibles taxonómicamente como en astillas, confirman la explotación de amplio espectro, en la que la diversidad de especies de bajo rendimiento es indicativa de un posible proceso de intensificación. También se han detectado marcas en Camelidae, que pueden vincularse a extracción de médula ósea. A diferencia de otros sitios del piedemonte y la planicie noreste (Chiavazza, 2019), los restos de peces indican índices de dominancia bajos, pero una presencia cuantitativamente relevante.

La integración de la evidencia arqueobotánica y zooarqueológica del sitio da cuenta de la explotación de recursos locales accesibles en ambientes con disponibilidad de agua, especialmente humedales con buena productividad. Los restos antracológicos y de micromamíferos indican correspondencia con comunidades del desierto de Monte, específicamente ambientes arbustivos y arbóreos, densos y complejos, cercanos a cuerpos de agua permanente. En correspondencia con esta evidencia, los restos de peces y aves indicarían un entorno tipo parche, tal como se ha propuesto para otros ambientes del norte de Mendoza (Chiavazza, 2015). Esto permite pensar exploratoriamente que los cauces aluvionales (zanjones) ubicados en el piedemonte del norte mendocino formaron un paisaje con disponibilidad de agua y ambientes de humedal, lo que habría sido fundamental para la subsistencia en esta área caracterizada por condiciones generales de aridez. La evidencia histórica y arqueológica acompaña esta idea: se planteó la presencia de ocupaciones humanas en torno a antiguas lagunas y humedales en el piedemonte normendocino y su intersección con la llanura (Prieto y Chiavazza, 2006; Rusconi, 1962); los estudios sobre restos micromamíferos indican la existencia de ambientes de humedal, distintos a los actuales, en el piedemonte y planicie del COA (López y Chiavazza, 2021).

La tecnología lítica de las ocupaciones tempranas expresa el uso predominante de materias primas de calidades medias y bajas pero ubicuas. La diversidad es baja y sobresale la homogeneidad en cuanto a materias primas explotadas y el predominio de las cuarcitas locales, lo que afirma una idea de movilidad bastante restringida. Se registraron escasos restos derivados de trabajos de talla secundaria y mayormente se observan residuos de talla primaria (reducción de núcleo y núcleos descartados), con importante porcentaje de ecofactos y prácticamente sin estandarización de artefactos. Tampoco se observan restos de reactivación. Los tamaños y la reserva de corteza indican poca economía de recursos disponibles en las inmediaciones. Destacan los filos abruptos con retoque unifacial. Por otra parte, los instrumentos poseen un neto perfil destinado al procesamiento, ya que, salvo un gancho de propulsor, no existen evidencias de caza (no hay puntas de proyectil). Este último elemento es excepcional, pues está elaborado en combarbalita, materia prima del Norte Chico chileno cuya presencia en la provincia se 
encuentra en contextos relativamente sincrónicos al sitio $\mathrm{MB}$, pero como parte de ajuares funerarios (p.e., el enterratorio Usina Sur en Uspallata) (Schobinger, 1974-1976). Este artefacto en el contexto de circulación de bienes probablemente tuvo una valoración no solo utilitaria, evidencia que se suma a la presencia de un adorno personal (cuenta) confeccionado en material malacológico. Por otra parte, la cantidad de manos de moler recuperadas es significativa, lo que, junto con la evidencia arqueobotánica, permite inferir actividades relacionadas con el procesamiento. Las tendencias generales del material lítico indican que el sistema de producción posee atributos relacionados con un proceso de intensificación que evidencia la disminución de la movilidad y el énfasis en la producción de herramientas con materiales de disponibilidad inmediata y enrolada dentro de estrategias expeditivas. En conjunto, los restos líticos, zooarqueológicos y antracológicos señalan una disminución de radios de movilidad en relación a los propuestos para los grupos cazadores-recolectores de precordillera durante el Holoceno Medio y la primera parte del Tardío (Chiavazza y Cortegoso, 2004).

La cerámica recuperada en la casa semisubterránea (Rasgo 3), es una de las evidencias alfareras más tempranas del COA, y su presencia en un contexto fechado en torno a los 2100 años AP la ubica en sincronía con la evidencia alfarera temprana recuperada en otras casas semisubterráneas y contextos del piedemonte (Bárcena, 1998; Chiavazza, 2005; Marsh, 2017). Esta tecnología se utilizó durante los mil años que duró la ocupación del sitio. La temprana adopción de la cerámica habría implicado ventajas adaptativas y posibles indicadores de procesos de intensificación, relacionados con el procesamiento de alimentos con bajo rendimiento calórico, lo que supuso mayores costos de procesamiento y el almacenamiento. Las huellas de uso por termoalteración en los fragmentos que presentan punto tangencial vertical (uniones borde-cuello y cuello-cuerpo) indican la exposición sobre el fuego, posiblemente para cocinar. Esto es compatible con la presencia de microrrestos de maíz y algarrobo en el depósito de hollín de uno de los fragmentos de forma indeterminada (Prieto-Olavarría et al., 2019). En el caso de estas huellas de hollín gruesas y fuertemente adheridas detectadas en el conjunto, se plantea que se produjeron por la preparación de alimentos mediante el hervido (Skibo, 2015), lo que puede ser interpretado como parte de los mayores costos de procesamiento. Además, las vasijas tienen ventajas tecnológicas en comparación con otro tipo de contenedores (p.e., de cuero o madera), ya que permiten la optimización del flujo de nutrientes y amplían el rango de potenciales recursos alimenticios que necesitan ser hervidos para ingerirse, como el maíz y la extracción de la médula de los huesos (Arnold, 1985). Esto también haría posible el procesamiento de alimentos de bajo rendimiento calórico. Hay que mencionar que, en relación a los costos de extracción y procesamiento de productos vegetales, se propone que la presencia del binomio tecnológico incorporación cerámica/aumento de artefactos de molienda fue parte de las estrategias de las sociedades en proceso de intensificación (Neme, 2007). En cuanto a las implicancias tecno-económicas e indicadoras del proceso de intensificación relacionadas con las transformaciones en la organización tecnológica y el impacto en la movilidad (Binford, 1981; Bettinger, 1994), es posible plantear preliminarmente la producción local, ya que se encontraron abundantes nódulos de arcilla y arena que indicarían procesamiento de materias primas, pero será necesario hacer estudios composicionales para aproximarse a la proveniencia de las vasijas usadas en el sitio. Por otra parte, la posibilidad de la práctica de almacenamiento en las vasijas cerámicas habría tenido un rol relevante en contextos tempranos si se considera que esta estrategia minimiza el riesgo en respuesta al desajuste de la relación población-recursos y a los procesos de sedentarización (Keeley, 1988). Desde una perspectiva social del proceso de intensificación temprana (Bender, 1978), la presencia de cerámica con decoración incisa, modelada y de pastillaje podría indicar una función relacionada con la comunicación, aspecto que debe ser profundizado en 
futuras investigaciones y tal como se ha realizado para la alfarería del período de dominación inca y colonial temprano (Prieto-Olavarría y Tobar, 2018).

La evidencia analizada permite aportar preliminarmente a la discusión sobre el proceso de intensificación en el COA, considerando que el surgimiento de los procesos de complejidad social e intensificación debe analizarse a la luz de la transformación de todo el conjunto de estrategias socioeconómicas (Politis et al., 2001) y de la particularidad histórica y social de cada contexto (Stoessel y Martínez, 2014). Se plantea que la causa del desarrollo del proceso de intensificación en la región habría sido el aumento en la presión demográfica regional y el consecuente impacto de las poblaciones humanas sobre la estructura regional de recursos, lo que se tradujo en la mayor explotación del paisaje, la disminución de los recursos altamente ranqueados y la subsistencia orientada a la obtención de alimentos con bajos rendimientos calóricos y mayores costos de procesamiento (Gil et al., 2006; Neme, 2007). En el caso particular del sitio $\mathrm{MB}$, existen indicadores (Binford, 1981; Bettinger, 1994) que aportan a la discusión sobre el proceso de intensificación en el área: existencia de ambientes que favorecieron la concentración de recursos y la disminución de la movilidad; desarrollo de tecnología lítica expeditiva; ampliación de la base de subsistencia tanto en recursos animales como vegetales; explotación de alimentos con bajos rendimientos calóricos (animales de pequeño tamaño); mayores costos de procesamiento y baja incidencia de la explotación de recursos altamente ranqueados. Con base en esto, la evidencia del sitio MB presenta correspondencia con los antecedentes del área, los que se insertan en el proceso de intensificación económica definido para el Cono Sur entre los 3000 y 1500 ańos AP, cuando se produjeron importantes transformaciones del modo de vida cazador-recolector que caracterizó la subsistencia durante gran parte del Holoceno (Politis et al., 2001; Cortegoso, 2006; Neme, 2007; Gil, Giardina et al., 2014; Stoessel y Martínez, 2014; Morgan, 2015).

\section{Conclusiones}

La posibilidad de realizar una excavación en área abierta en el sitio MB y detectar 15 rasgos con distintas funcionalidades en pleno centro cívico de la ciudad de Mendoza, sector que contaba con escasas referencias arqueológicas, es un hito en la arqueología urbana regional. Desde esta perspectiva, la evidencia recuperada es clave para comprender los procesos de ocupación y desarrollo de las poblaciones en el piedemonte del norte de Mendoza.

Los fechados indican que hace ca. 2100 años AP se produjo la ocupación humana del sitio MB, una de las más tempranas registradas en el piedemonte mendocino. Este proceso se extendió por mil ańos y se realizó a partir de la incorporación de dos desarrollos tecnológicos novedosos: la construcción de casas semisubterráneas y la incorporación de la cerámica, evidencia que comparte con otros sitios tempranos del piedemonte (Barrancas y Casa de San Martín). Desde esta perspectiva, los fechados en torno a los 2000 años AP obtenidos de la casa semisubterránea Rasgo 3 indican que la cerámica asociada es una de las más tempranas registradas en la región.

Los resultados obtenidos del registro arqueobotánico y zooarqueológico del sitio permiten inferir la explotación de recursos de ambientes de humedal, actualmente inexistentes, lo que se relaciona con las evidencias aportadas por la historia y la zooarqueología sobre la existencia pasada de lagunas y humedales en el piedemonte y tierras bajas del norte de Mendoza.

Los resultados obtenidos y analizados en relación a los antecedentes existentes para la región hacen posible plantear preliminarmente que la ocupación del sitio se habría dado en el marco 
de un proceso de intensificación regional. Los principales indicadores que evidencian cambios respecto a los modos de vida centrados en la caza y la recolección se relacionan con la ocupación de este ambiente de piedemonte y la reducción de la movilidad: los cambios tecnológicos sintetizados en la adopción de la cerámica y el uso de materias primas líticas de disponibilidad inmediata y con poca intensidad en la talla; la construcción de estructuras habitacionales (casas semisubterráneas); la explotación de alimentos con bajos rendimientos calóricos y mayores costos de procesamiento. Con posterioridad a las ocupaciones tempranas, se dio un proceso de abandono del sector, relacionado con procesos agradacionales que implicaron el depósito de 2 $\mathrm{m}$ de sedimentos, para volver a ser ocupado hace unos 500 ańos en concordancia con la dominación inca y la conquista. Desde esta perspectiva, este sitio ofrece evidencias para indagar a futuro las causas ambientales que pudieron incidir en el lapso que se registra entre los ca. 1300 y 400 años AP, cuando un fuerte aporte sedimentario pudo ser crucial en la discontinuidad ocupacional de este sector del piedemonte.

\section{Agradecimientos}

Agradecemos a los miembros del Centro de Investigaciones Ruinas de San Francisco (CIRSF), Área Fundacional de Mendoza, Municipalidad de Mendoza. A las fuentes de financiamiento SECTyP, Universidad Nacional de Cuyo, proyecto SECTyP 06/G490 "Procesos sociales y ambientales en el sector urbano de Mendoza entre los siglos XV-XVIII: Arqueología Urbana e Historia Ambiental”; FONCYT, Agencia Nacional de Promoción Científica y Tecnológica, proyecto PICT 2013-00190 "Arqueología e historia urbana. Mendoza entre los siglos XVXVIII". A los evaluadores, que con sus comentarios ayudaron a mejorar este trabajo.

\section{Referencias citadas}

Abraham, E. (2000). Geomorfología de la Provincia de Mendoza. En Abraham, E. y Rodríguez Martínez, F. (Eds.). Argentina. Recursos y problemas ambientales de la zona árida. Primera Parte. Provincias de Mendoza, San Juan y La Rioja. Tomo I (pp. 29-48). Espańa y Argentina: Universidad de Granada - IADIZA, SDSyPA.

Arnold, D. (1985). Ceramic Theory and Cultural Process. Cambridge: Cambridge University Press.

Aschero, C. (1983). Ensayo para una clasificación morfológica de artefactos líticos aplicada a estudios tipológicos comparativos. Apéndices A-C. Revisión. Cátedra de Ergología y Tecnología, Facultad de Filosofía y Letras, Universidad de Buenos Aires, Buenos Aires. Inédito.

Bárcena, J. y Roig, F. (1981-1982). Investigaciones arqueológicas en el área puneña de Mendoza, con especial referencia a tephfocactus Tephrocactus andicola (Cactaceae) como nuevo recurso alimentario. Relaciones de la Sociedad Argentina de Antropología, 14(2), 85-107.

Bárcena, R. (1998) Arqueología de Mendoza. Las Dataciones Absolutas y sus Alcances. Mendoza: EDIUNC.

Bagnouls, F. y Gaussen, H. (1957). Les climats biologiques et leur classification. Annales de Géographie, 355, $193-220$.

Bender, B. (1978). Gatherer-hunter to farmer: a social perspective. World Archaeology, 10(2), 204-222.

Bettinger, R. (1994). From Traveler to Processor: Regional Trajectories of Hunter-Gatherer Sedentism in the Inyo-Mono Region. En Billman, B. R. y Feinman, G. M. (Eds.). Fifty Years Since Viru: Theoretical 
Advances and Contributions of Settlement Pattern Studies in the Americas (pp. 39-55). Washington, DC: Smithsonian Institution Press.

Binford, L. (1981). Bones: Ancient Men and Modern Myths. New York, NY: Academic Press.

Canals Frau, S. (1956). Algunos Aspectos de la Cultura de Agrelo. Anales de Arqueología y Etnología, 12, $7-18$.

Castro, M. A. (1994). Maderas argentinas de Prosopis: atlas anatómico. Buenos Aires: Secretaría General de la Presidencia de la Nación.

Chiavazza, H. (1995). Estudios Arqueológicos en el sitio "Rincón de Los Helados" ("RH"). Ocupación Multicomponente en Noreste de Pampa de Canota - Departamento de Las Heras, Provincia de Mendoza, República Argentina. Tesis de Licenciatura, FFyL, Universidad Nacional de Cuyo, Mendoza, Argentina.

Chiavazza, H. (2005). Los templos coloniales como estructuras funerarias. Arqueología en la iglesia jesuita de Mendoza. Londres: British Archaeological Reports. 1388.

Chiavazza, H. (2007). Cambios ambientales y sistemas de asentamiento en el árido normendocino. Arqueología en los paleocauces del rio Mendoza. Tesis doctoral. Facultad de Ciencias Naturales y Museo, Universidad Nacional de La Plata, La Plata, Argentina.

Chiavazza, H. (2010). Arqueología Histórica de la ciudad de Mendoza: explorando vínculos con Chile. En Actas del XVII Congreso Nacional de Arqueología Chilena, Valdivia, 2006, 2 (pp. 1047-1058). Sociedad Chilena de Arqueología, Universidad Austral de Chile.

Chiavazza, H. (2013). “No tan simples”: pesca y horticultura entre grupos originarios del norte de Mendoza. Comechingonia virtual. Revista Electrónica de Arqueología, 7(1), 27-45.

Chiavazza, H. (2014). Tendencias regionales del registro arqueológico en sociedades sin estructura aldeana del Noreste de Mendoza. En Falabella, F., Sanhueza, G. L., Cornejo, R. L. y Correa, B. I. (Eds.). Distribución espacial en sociedades no aldeanas: del registro arqueológico a la interpretación social (pp. 221-249). Santiago, Chile: Serie Publicaciones Monográficas de la Sociedad Chilena de Arqueología 4.

Chiavazza, H. (2015). Pescadores y horticultores ceramistas del valle de Mendoza. Xama. Serie Monografías, $5,45-62$.

Chiavazza, H. (2019). Ocupaciones humanas en el Monte Árido III (OHMA_III): variabilidad arqueológica en escenarios diferenciados del Monte entre los 2000 y 300 ańos AP. Jornadas de Ciencia Técnica y Posgrado de la UNCuyo. Mendoza, Argentina.

Chiavazza, H. y Cortegoso, V. (2004). De la cordillera a la llanura. Disponibilidad regional de recursos líticos y organización de la tecnología en el norte de Mendoza. Chungara. Revista de Antropología Chilena, $36,723-737$.

Chiavazza, H., Frías, C., Puebla, L. y Acosta, A. (2008). Cazadores recolectores del piedemonte mendocino en el 3.000 AP (Puesto Lima, Quebrada de Papagayos). Anales de Arqueología y Etnología, 61-62, 203-240.

Chiavazza, H. y Mafferra, L. (2007). Estado de las investigaciones arqueobotánicas en Mendoza y sus implicancias en la arqueología histórica. Revista de Arqueología Histórica Latinoamericana y Argentina, 1, $127-152$. 
Chiavazza, H., Prieto-Olavarría, C., Puebla, L., Quiroga, M., Anzorena, J. y Bontorno, E. (2019). Asentamiento y cronología en el valle de Mendoza entre 2100-1300 AP. En Costa, T. (Ed.). Libro de Resúmenes XX Congreso Nacional de Arqueología Argentina: 50 años de arqueologías (pp. 51-56). Recuperado de https://suquia.ffyh.unc.edu.ar/handle/suquia/

Collins, M. (1975). Lithic Technology as Means of processual Inference. En Swanson, E. (Ed.). Lithic Technology: Making and Using Stone Tools (pp. 15-34). The Hague - París: Mouton Publishers.

Corbat, M., Zangrando, A. F., Gil, A. y Chiavazza, H. (2017). Explotación de peces e intensificación en ambientes áridos: comparando el registro de humedales en humedales del centro occidente de Argentina. Latin American Antiquity, 28(2), 196-212. doi:10.1017/laq.2017.21

Cornejo, L. y Sahueza, L. (2003). Coexistencia de cazadores recolectores y horticultorestempranos en la cordillera andina de Chile Central. Latin American Antiquity, 14, 389-407. doi:10.2307/3557575

Cortegoso, V. (2006). Comunidades agrícolas en el Valle de Potrerillos (NO de Mendoza) durante el Holoceno tardío: organización de la tecnología y vivienda. Intersecciones en Antropología, 7, 77-94.

Cortegoso, V., Lucero, G., Castro, S. y Winocur, D. (2017). Bosques fósiles y tecnología humana: la explotación de materias primas líticas en el Bosque de Darwin, Paramillos (Argentina). Latin American Antiquity, 28(3), 1-20. doi:10.1017/laq.2017.20

Durán, V. (2000). Poblaciones indigenas de Malargüe. Mendoza: Editorial Facultad Filosofía y Letras, Universidad Nacional de Cuyo.

Durán, V., Cortegoso, V., Chiavazza, H., Lagiglia, H. y García, A. (2002). Proyecto Potrerillos-Fase II-Relevamiento y Rescate Arqueológico en el Área del Emprendimiento. Informe Final. Instituto de Estudios, Asesoramiento y Servicios. Facultad de Filosofía y Letras. Universidad Nacional de Cuyo, Mendoza. Inédito.

Ericson, J. E. (1984). Toward the analysis of lithic production systems. En Ericson, J. E. y Purdy, B. (Eds.). Prehistoric Quarries and Lithic Production (pp. 1-19). Cambridge: Cambridge University Press.

Gambier, M. (1977). La Cultura de Ansilta. Instituto de Investigaciones Arqueológicas y Museo, Universidad Nacional de San Juan, San Juan, Argentina.

Gambier, M. (1993). Prehistoria de San Juan. San Juan: Editorial Fundación de la Universidad de San Juan.

García, A. (1992). Hacia un ordenamiento preliminar de las ocupaciones prehistóricas agrícolas precerámicas y agroalfareras en el Noroeste de Mendoza. Revista de Estudios Regionales CEIDER, 10, 7-34.

García, A. (2003). Los primeros pobladores de los Andes Centrales Argentinos. Una mirada a los estudios sobre los grupos cazadores-recolectores tempranos de San Juan y Mendoza. Mendoza: Zeta.

García, A. (2010). Arqueología prehistórica de San Juan. Universidad Nacional de San Juan, Argentina.

Gasco, A., Marsh, E., Frigolé, C., Castro, S., Privitera, C., Moyano, R. y Yebra, L. (2011). Actividades domésticas durante los siglos III-VIII d.C. en el valle de Potrerillos (San Ignacio-Mendoza). Un acercamiento desde la osteometría y la tecnología cerámica y lítica. Revista del Museo de Antropología, 4, 145-160.

Gil, A., Giardina, M., Neme, G. A. y Ugan, A. (2014). Demografía Humana e Incorporación de Cultígenos en el Centro Occidente Argentino: Explorando Tendencias en las Fechas Radiocarbónicas. Revista Española de Antropología Americana, 44(2), 523-553. doi:10.5209/rev_REAA.2014.v44.n2.50728 
Gil, A. F., Tykot, R. H., Neme, G. y Shelnut, N. R. (2006). Maize on the frontier. Isotopic and macrobotanical data from central-western Argentina. En Staller, J., Tykot, R. y Benz, B. (Eds.). Histories of maize. Multidisciplinay Approaches to the Prehistory, Linguistics, Biogeography, Domestication and Evolution of Maize (pp. 199-214). New York: Academic Press.

Gil, A. F., Villalba, R., Ugan, A., Cortegoso, V., Neme, G., Michieli, C. T., Novelino, P. y Durán, V. (2014). Isotopic Evidence on Human Bone for Declining Maize Consumption During the Little Ice Age in Central Western Argentina. Journal of Archaeological Science, 49, 213-227. doi:10.1016/j.jas.2014.05.009

Hammer, O., Harper, D. y Ryan, P. (2001). PAST: Paleontological Statidstics software package for education and data analysis. Paleontología Electrónica, 4(1), 9.

InsideWood (2004). The InsideWood Database. Recuperado de http://insidewood.lib.ncsu.edu/search

Keeley, L. H. (1988). Hunter-Gatherer Economic Complexity and Population Pressure: A Cross-Cultural Approach. Journal of Anthropological Archaeology, 7, 373-411. doi:10.1016/0278-4165(88)90003-7

Lagiglia, H. (2001). Los Orígenes de la Agricultura en la Argentina. En Berberian, E. E. y Nielsen, A. E. (Eds.). Historia Argentina Prehispánica (pp. 41-81). Córdoba: Brujas.

López, J. M. (2018). Restos óseos de micromamíferos recuperados en sitios arqueológicos del norte de Mendoza para contextos correspondientes al Holoceno tardio: un enfoque zooarqueológico, tafonómico y paleoambiental. Tesis de doctorado. FFyL, Universidad Nacional de Cuyo, Mendoza.

López, J. M. y Chiavazza, H. (2021). Ancient wetlands in the arid environments of Central Western Argentina: a palaeoecological perspective based on archaeological small mammal remains. Journal of South American Earth Sciences, 106. doi.org/10.1016/j.jsames.2020.103023

Mafferra, L. (2009). Arqueobotánica del Norte de Mendoza. Interpretaciones sobre el rol de los vegetales en la interacción indigena-hispana durante el siglo XVI. Tesis de licenciatura. FFyL, Universidad Nacional de Cuyo, Mendoza.

Mafferra, L. (2015). Arqueología de los paisajes forestales del norte de Mendoza. Tesis de doctorado. FFyH, Universidad Nacional de Córdoba, Córdoba.

Mafferra, L., Roig, F. A. y Piraino, S. (2013). Las mil y un similitudes y las tres diferencias entre Acacia Mill. y Prosopis L. en el Centro Oeste Argentino. En Lema, V. y Belmar, C. (Eds.). Avances y desafíos metodológicos en arqueobotánica: miradas consensuadas y diálogos compartidos desde Sudamérica (pp. 419-431). Santiago: Editorial Universidad SEK.

Marsh, E. (2017). La fecha de la cerámica más temprana en los Andes sur. Una perspectiva macrorregional mediante modelos bayesianos. Revista del Museo de Antropología, Suplemento Especial 1, 83-94. doi:10.31048/1852.4826.v10.n0.13501

Mengoni Goñalons, G. L. (2010). Zooarqueología en la práctica: algunos temas metodológicos. Xama, 19, 83-113.

Morgan, C. (2015). Is it Intensification Yet? Current Archaeological Perspectives on the Evolution of Hunter-Gatherer Economies. Journal of Archaeological Research, 23, 163-213. doi:10.1007/s10814-0149079-3 
Morgan, C., Neme, G., Sugrañes, N., Salgan, L., Gil, A. F., Otaola, C. y Llano, C. (2017). Late Prehistoric High-Altitude Hunter-Gatherer Residential Occupations in the Argentine Southern Andes. Journal of Field Archaeology, 42(3), 214-227. doi:10.1080/00934690.2017.1308749

Neme, G. (2007). Cazadores-recolectores de Altura en los Andes Meridionales: el Alto Valle del Río Atuel. Oxford, Reino Unido: BAR International Series 1591.

Neme, G. y Gil, A. F. (2008). Biogeografía Humana en Los Andes Meridionales: Tendencias Arqueológicas en el Sur de Mendoza. Chungara. Revista de Antropología Chilena, 40, 5-185.

Neme, G. y Gil, A. F. (2009). Human Occupation and Increasing Mid-Holocene Aridity. Current Anthropology, 50(1), 149-163. doi:10.1086/596199

Ots, M. J., Aguilar, J. P., Cahiza, P. A. y García Llorca, J. (2016). Recursos y estrategias de consumo en el Centro de Mendoza entre los siglos X-XVI AD. Intersecciones en Antropología, 17, 375-387.

Pastor, S., Medina, M. y Berberián, E. (2013). Poblados, casas y maizales. Arqueología del espacio residencial y productivo en las Sierras Centrales de Argentina (ca. 1100-300 AP). Revista Española de Antropología Americana, 43(1), 31-55. doi:https://doi.org/10.5209/rev_REAA.2013.v43.n1.42297

Piqué i Huerta, R. (1999). Producción y uso de combustible vegetal: una evaluación arqueológica. Treballs d'Etnoarqueologia 3. Editorial CSIC

Planella, M. T. y Tagle, B. A. (2004). Inicios de presencia de cultígenos en la zona central de Chile, períodos Arcaico y Agroalfarero Temprano. Chungara. Revista de Antropología Chilena, 36, 387-399.

Politis, G., Martínez, G. y Bonomo, M. (2001). Alfarería Temprana en Sitios de Cazadores-Recolectores de la Región Pampeana (Argentina). Latin American Antiquity, 12(2), 167-181. doi:10.2307/972054

Prieto, M. del R. y Chiavazza, H. (2006). Aportes de la Historia Ambiental y la Arqueología para el análisis del patrón de asentamiento huarpe en el oasis norte de Mendoza. Anales del Instituto de Arqueología y Etnología, 59-60, 163-196.

Prieto, M. del R. y Wuilloud, C. F. (1986). Consecuencias ambientales derivadas de la instalación de los españoles en Mendoza en 1561. Cuadernos de historia regional, 2(6), 3-35.

Prieto Olavarría, C., Chiavazza, H., Castillo, L., Tobar, V., Bontorno, E. y Porta, V. (2017). Estado Actual de las investigaciones de la cerámica arqueológica del norte de Mendoza: tecnología, cronología y distribución. Revista del Museo de Antropología, Suplemento Especial, 1, 95-104. doi:10.31048/1852.4826.v10. n0.13525

Prieto-Olavarría, C., Chiavazza, H. y Musaubach, G. (2019). Microrrestos de vegetales cultivados y silvestres en fragmentos cerámicos. Primeras evidencias en el Centro Occidente Argentino. Revista Arqueología, 25(1), 221-231. doi:10.34096/arqueologia.t25.n1.6015

Prieto-Olavarría, C. y Tobar, V. (2018). Interacciones y lenguajes visuales en la cerámica local de contextos del período de dominación incaica y coloniales (Centro Oeste Argentino). Estudios Atacameños. Arqueologia y Antropologia Surandinas, 55, 135-161.

Rice, P. (1987). Pottery analisys: a source book. Chicago, IL: University of Chicago Press. 
Roig, F. (1972). Bosquejo fisonómico de la vegetación de la provincia de Mendoza. Boletín de la Sociedad Argentina de Botánica, 13, 49-80.

Roig, F. A. (1976). Las comunidades vegetales del piedemonte de la precordillera de Mendoza. ECOSUR, 3(5), 1-45.

Roig, F. A., Martínez Carretero, E. y Méndez, E. (2000). Vegetación de la Provincia de Mendoza. En Abraham, E. y Rodríguez Martínez, F. (Eds.). Recursos y problemas ambientales de la zona árida. Primera Parte. Provincias de Mendoza, San Juan y La Rioja. Tomo 1 (pp. 59-62). Mendoza y Andalucía: Junta de Gobierno de Andalucía - Universidades y Centros de Investigación de la Región Andina Argentina, Mendoza.

Rusconi, C. (1956). Restos Arqueológicos en la ciudad de Mendoza. Revista del Museo de Historia Natural, 6, 129-135.

Rusconi, C. (1962). Poblaciones Pre y post hispánicas de Mendoza. Arqueología. Volumen III. Mendoza: Edición Oficial.

Rye, O. (1981). Pottery Technology. Washington, DC: Taraxacum.

Scheel-Ybert, R. (2004). Teoria e métodos em antracologia. Consideraçóes teóricas e perspectivas. Arquivos do Museu Nacional, 62(1), 3-14.

Shepard, A. (1976 [1956]). Ceramic for the archaeologist. Washington, DC: Carnegie Institution of Washington.

Schlanger, S. (1992). Recognizing Persistent Places in Anasazi Settlement System. En Rossignol, J. y Wandsnider, L. A. (Ed.). Space, Time, and Archaeological Landscapes (pp. 91-111). Nueva York, NY: Plenum Press.

Schobinger, J. (1974-1976). El enterratorio Uspallata Usina sur (Prov. de Mendoza): el estudio de su ajuar funerario. Anales de Arqueología y Etnología, 29-31, 67-89.

Skibo, J. (1992). Pottery Function. A Use-Alteration Perspective. New York, NY: Plenum Press.

Skibo, J. (2015). Pottery Use Alteration Analisys. En Marreiros, J. M., Gibaja Bao, J. F. y Ferreira Bicho, N. (Eds.). Use-wear and Residue Analysis in Archaeology. Manuals in Archaeological Method, Theory and Technique (pp. 189-198). Suiza: Springer.

Stoessel, L. y Martínez, G. (2014). El proceso de intensificación en la transición pampeano patagonica oriental. Discusión y perspectivas comparativas con regiones aledańas. Comechingonia Revista de Arqueologia, 18, 65-94.

Stuiver, M., Reimer, P. y Reimer, R. W. (2005). CALIB 5.0. Manual, CALIB 5.0 Manual. Recuperado de http://www.calib.org

Vaccarino Pasquali, E. L. B., Manduca, F. R., Bizzoto, F. S. y Vich, A. I. J. (2012). Morfometría de cuencas ubicadas en el piedemonte mendocino de la precordillera. En Lopardo (Presidencia), IFRH 2012 1er Encuentro de investigadores en formación en Recursos Hidricos. Ezeiza, Bs. As., Argentina. https://www.ina.gov.ar/ ifrh-2012/?seccion=3 